المجلة الدولية للدراسات التربوية والنفسية

بحث رقم 10

المجلد التاسع، العدد الثالث، 897:879

حزيران (2021)

\title{
فعالية برنامج قائم على التعلم التعاوندي وأثثره في تنمية تحقيق الذات لدي طلاب المرحلة الثانوية
}

\author{
نجلاء فتحي عبد الرحمن الشيمي
}

أستاذ مساعد علم النفس والصحة النفسية كلية العلوم والآداب شروره جامعة نجران- المملكة العربية السعودية aldoktor_2014@yahoo.com 


\title{
فعالية برنامج قائم على التعلم التعاوني و أثره في تنمية تحقيق الذات لدي طلاب المرحلة الثانوية
}

\author{
نجلاء فتحي عبد الرحمن الشيمي \\ أستاذ مساعد علم النفس والصحة النفسية كلية العلوم والآداب شروره- جامعة نجران- المملكة العربية السعودية السيكية \\ aldoktor_2014@yahoo.com
}

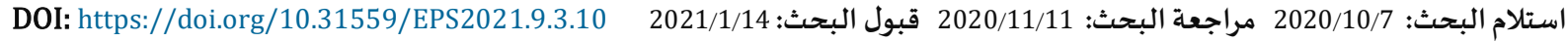
الملخص:

هدفت الدراسة إلى التحقق من فعالية برنامج تدريبي قائم على التعلم التعاوني في تنمية تحقيق الذات لدى طلاب الصف الثالث الثانوي، والتحقق من استمرار أثر البرنامج لدى العينة، وتكونت عينة الدراسة من (60) طالباً مقسمة إلى مجموعتين متكافئتين أحدهما

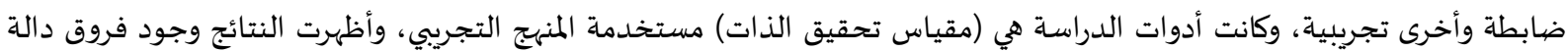
إحصائياً بين متوسط درجات المجموعتين التجريبية والضابطة على مقياس تحقيق الذات وأبعاده في القياس البعدي، لصالح المجموعة

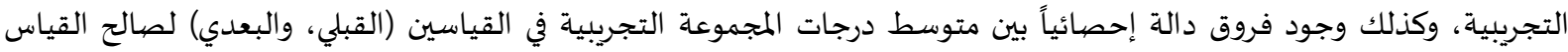
البعدي على مقياس تحقيق الذات وأبعاده وكذلك عدم وجود فروق ذات دلالة إحصائية بين متوسط درجات أفراد المجموعة التجريبية على إلى مقياس تحقيق الذات في القياسين البعدي والتتبعي، أي استمرارية فعالية البرنامج الذي تعرضت لله المجموعة التجريبية، ومن أهم

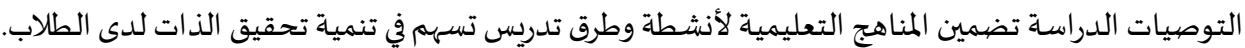
الكلمات المفتاحية: التعلم التعاوني؛ تحقيق الذات؛ برنامج تدريبي.

شهدت السنوات الأخيرة اهتماماً ملحوظاً من المؤسسات التربوية في مختلف دول العالم لتطوير الأساليب التي تدفع الفرد وتشجعه على القيام بمزيد من التفاعل، والمشاركة، والنشاط، والهدف من ذلك هو توفير بيئة تعلم تعاونية تتيح للفرد الفرصية للتفاعل مع زملائه، وتنمية الاتجاهات الإيجابية نحوهم، وتنمية روح التعاون لديهم. ويشير إبراهيم بهلول (2012: 14) إلى أهمية التعلم التعاوني ودوره في إكساب الأفراد بعض السهات السمات الدالة على الصحة النفسية مثل: النضج العاطفي، والعلاقات الاجتماعية الناجحة، والثقة بالآخرين، والاستقلالية، وتحمل المسؤولية، كما أنه ينمي الدافعية، ويزيد من الشعور بالثقة

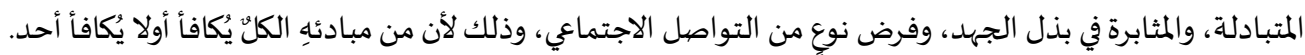

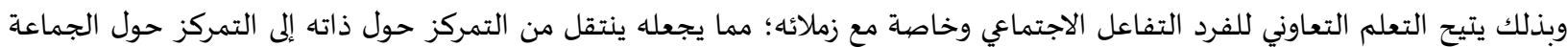
والفرد عندما يشارك أقرانه ويتعاون معهم تقل عنده نزعة الأنانية والعدوانية، وتنمى لدياه مفاهيم المشاركة، والتعاون، والاحترام، والشخصية الاجتماعية (Caissi, Wilson 2009: 109). وتؤيد ألفت فوده (2003: 90) أن فعالية التعلم خلال مجموعات صغيره تؤدى إلى الحصول على العديد من الخبرات، ولكي يتحقق التعلم

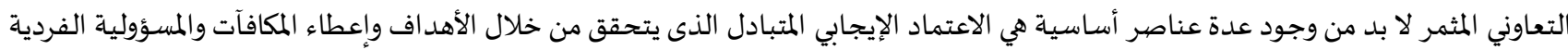
التي تؤكد على التمكن الفردي من التكليفات والتفاعل المباشر بين الطلاب، واستخدام المهارات الاجتماعية لإنجاز المهمة، والاستخدام السليم لمهارات التفكير، وجدير بالذكر أن التعاون يقلل من مستوى القلق لدى الطلاب ويزيد من مشاعر الأمن وينمي المهارات العديدة لدئى الطلاب. 
ويشير حمزة أبو النصر؛ محمد جمل (2005: 27) إلى أن التعلم التعاوني من خلال مجموعات صغيرة يمكن أن يطبق مع كل مستويات الطلاب

العمرية وكذلك كل مستويات التعلم من المرحلة الابتدائية وحتى الدراسة الجامعية.

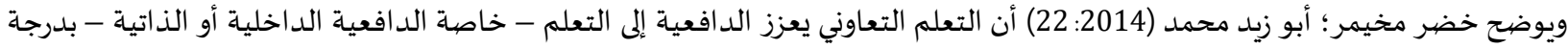

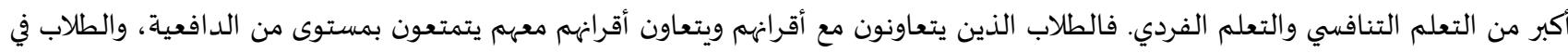

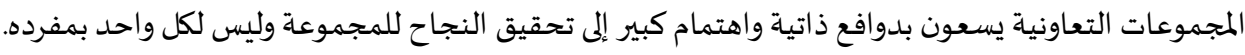

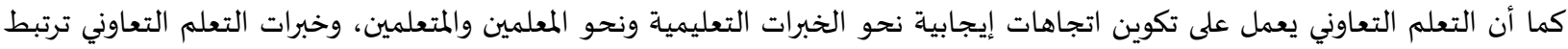

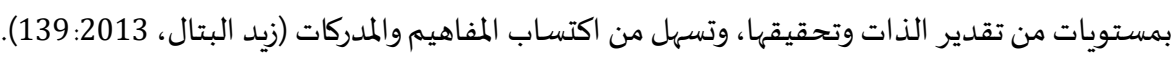

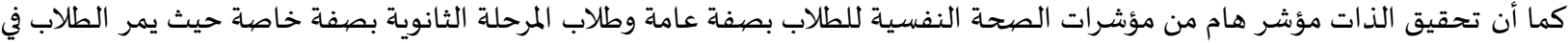

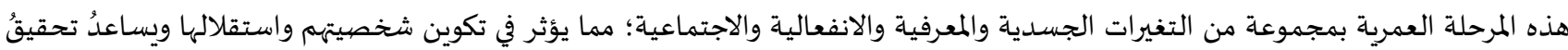

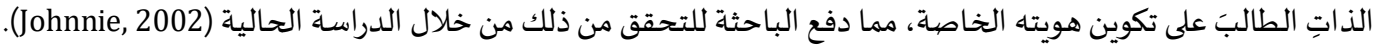

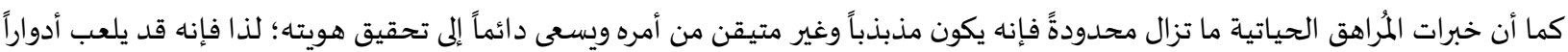

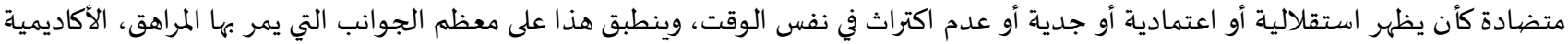

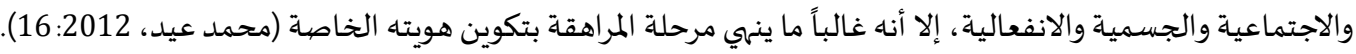

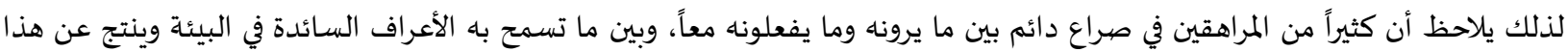

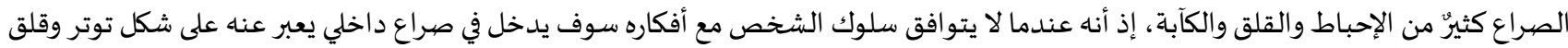

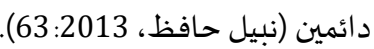

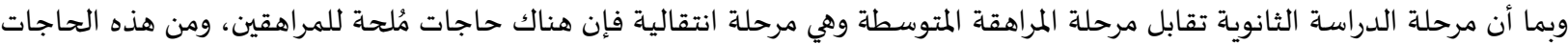

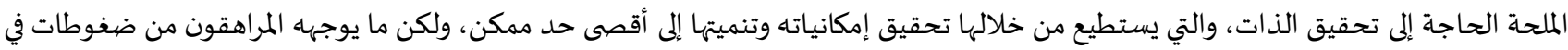

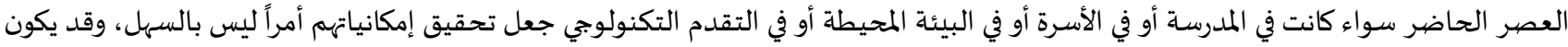

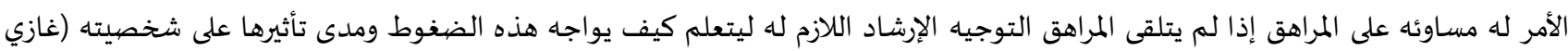

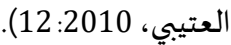

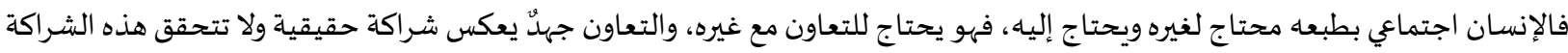

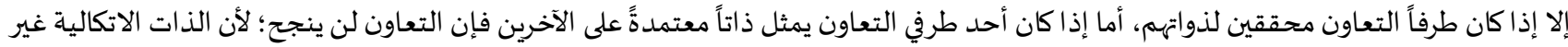

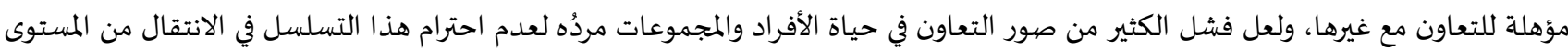

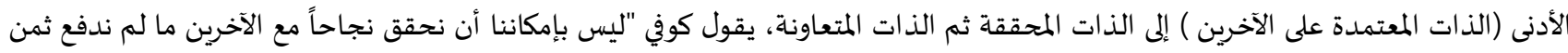

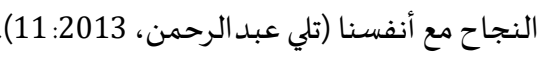

مشكلة الدراسة:

شهدت الآونة الأخيرة اهتمام بالطرق والأساليب التي تيسر عملية التعلم؛ مما أدى إلى ظهور العديد من أساليب وطرق التعلم التي تهتم بشكل

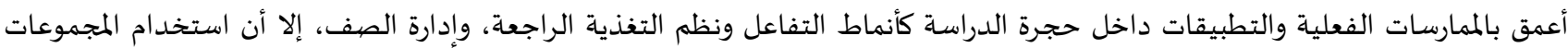

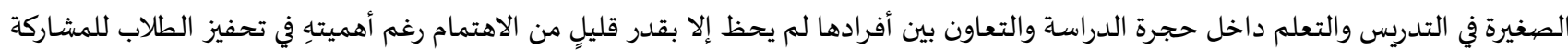

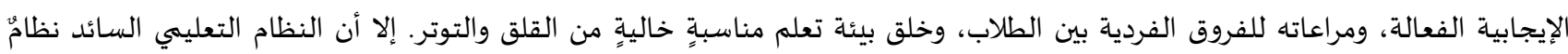

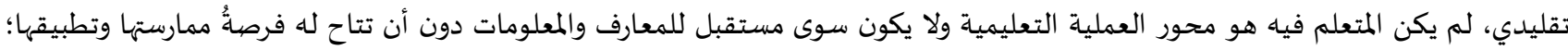

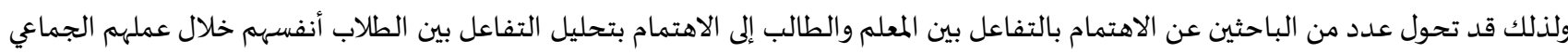

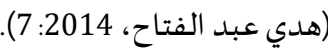

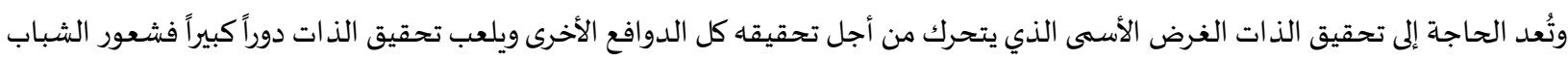

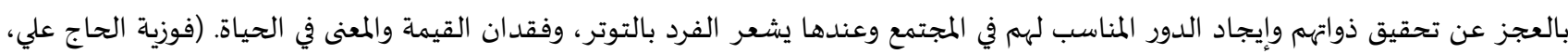

تنبثق مشكلة البحث من الربط بين أساليب التعلم وتحقيق الذات لدى المراهقين حيث أن ازدياد الضغوط النفسية وتأثيرها المباشر على

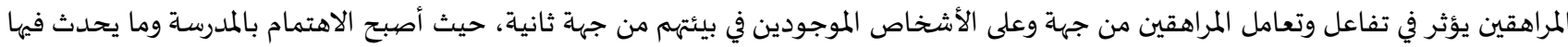
وما تحتويه من عناصر ضرورة تملهيا الظروف الاجتماعية والحضارة العالميانية. 
الأمر الذي يؤكد ضرورة الاهتمام بالعوامل التي تؤثر على العملية التعليمية في المدرسة، واكتشاف أشكال الاضطرابات النفسية مهما كانت

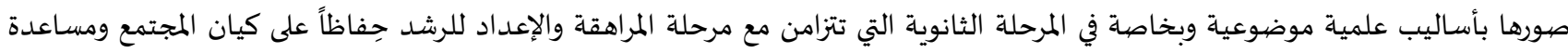

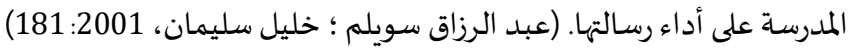
حيث أن مرحلة المراهقة تتسم بالعديد من التغيرات العضيوية والنفسية التي قد تبعث على القلق والتوتر، فإن تلك التغيرات التهات الإضيافية المتلاحقة

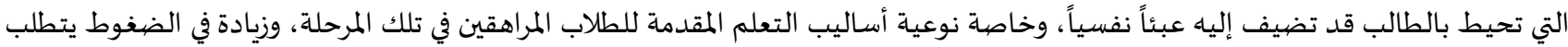
فهمها والتعامل معها بما يحقق له الاستقرار النفسي، وزيادة قدرته على التعامل الإيجابي، ومواجهة التحديات للوصول لجودة الحالة النفسية للطالب

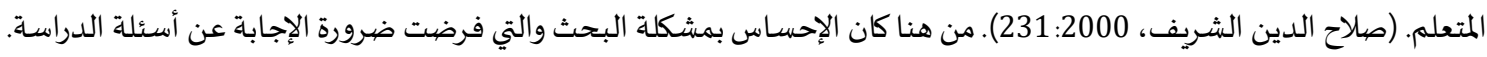

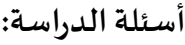

تحاول الدراسة الإجابة عن الأسئلة الاتية:

1. هل توجد فروق بين متوسطي درجات طلاب المجموعة التجريبية وطلاب المجموعة الضابطة في التطبيق البعدي لمقياس تحقيق الذات وأبعاده؟

2.

3. هل توجد فروق بين متوسط درجات طلاب المجموعاة التجريبية في التطبيق القبلي والتتبعي لمقياس تحقيق الذات وأبعاده؟

فروض الدراسة:

تختبر الدراسـة الفروض التالية:

1. توجد فروق ذات دلالة إحصائية عند مستوى دلالة (0.05) بين متوسطي درجات طلاب المجموعة التجريبية وطلاب المجموعة الضابطة في

التطبيق البعدي لمقياس تحقيق الذات وأبعاده تعزى لصالح المجموعة التجريبية".

2. توجد فروق ذات دلالة إحصائية عند مستوى دلالة (20.05) بين متوسط درجات طلاب المجموعة التجريبية في التطبيق القبلي والبعدي

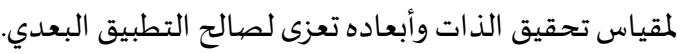

3. لا توجد فروق ذات دلالة إحصائية عند مستوى دلالة (0.05 م) بين متوسط درجات طلاب المجموعة التجريبية في التطبيق البعدي والتتبعي

لمقياس تحقيق الذات وأبعاده.

أهداف الدراسـة:

تهدف الدراسة الحالية إلى:

1. الكشف عن فعالية برنامج تدريبي (التعلم التعاوني) في تنمية تحقيق الذات لدى طلاب الصف الثالث الثانوي.

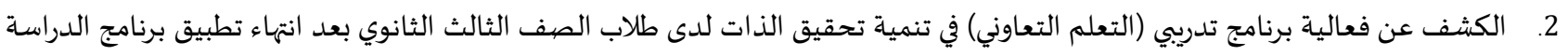

المستخدم.

أهميـة الدراسـة:

تستمد الدراسة الحالية أهميتها مما يلي:

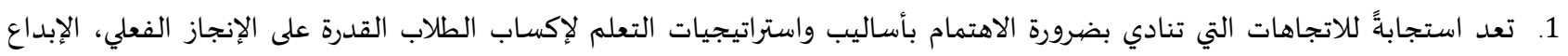

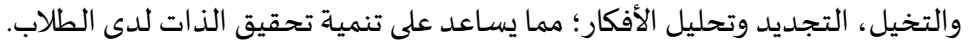

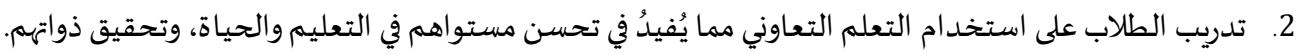

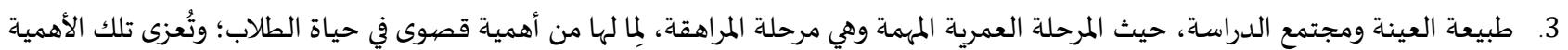

للتغيرات الفسيولوجية والتنموية التي تطرئ على الطلاب في هذه المرحلة.

4. توجاء نظر القائمين على العملية التعليمية الاهتمام ببناء استراتيجيات قائمة علي التعلم التعاوني؛ لما له عظيه الهيم الأثر في تعليم الطلاب والطلاب

وكافة المتعلمين في المراحل التعليمية المختلفة.

حسدود الدراسـة:

حدود موضوعية: انحصرت هذه الدراسة في التعرف على فاعلية برنامج (التعلم التعاوني)، وأثره في تنمية تحقيق الذات لدي طلاب المرحلة

الثانوية. 
حدود مكانية: تم تطبيق الدراسة في مدرسة بنها بمدينة (بنها). حدود زمانية: تم تطبيق الدراسـة في الفصل الدراسي الأول من عام 2019 / 2020م. حدود بشرية: اقتصرت هذه الدراسـة على عينة من طلاب الصف الثالث الثانوي.

المفاهيم الإجر ائية للدراسـة:

التعلم التعاوني: تعرفه الباحثة إجرائياً بأنه "نموذج تعليمي يشمل مواقف، وحوارات، وأنشطة اجتماعية، وطرق وأساليب متعلقة بالمادة الدراسية، يشترك فيها طلاب المرحلة الثانوية على شكل مجموعات صغيرةٍ، من طلاب ذوي مستويات تحصيلية مختلفة لتحقيق هدف محدد

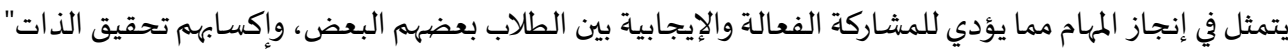

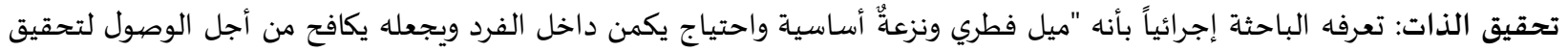

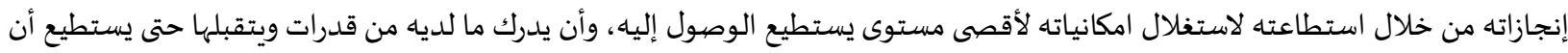
يثبت وجوده داخل أسرته أو بين الأقران، أي يحقق الفرد وجوده بالمجتمع الخارجي بالصورة التي يرى فيها ذاته.

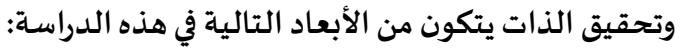

1. 2. التفاؤل: هو توقع الإنسان أن الغد أفضل من اليوم، وأن الغد أو المستقبل يحمل الكثير من بشائر الأمل والخير والتفاؤل للإنسان وأن

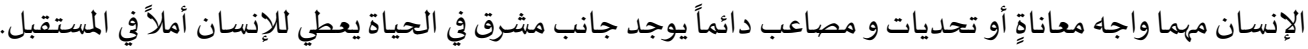
فاعلية الذات: هي مدى قدرة الفرد على التخطيط الجيد والتفكير السليم مع اتخاذ القرارات المناسبة وأيجاد طرق ووسائل ممكنة؛ بحيث يستطيع الفرد التعامل مع جميع المواقف. القدرة على الإنجاز: هي قدرة الفرد على إنجاز مهامه وأعماله ومسئولياته في الوقت المحدد مع قدرته على توظيف إمكاناته وقدراته من أجل بلوغ أهد افه، والمستوى الذي يتطلع إليه وتقاس درجة تحقيق الذات لدى الطلاب بالدرجة الكلية التي يحصل عليها الطالب على مقياس تحقيق الذات المستخدم في الدراسة أو على أي بعد من أبعاده.

الإطار النظري:

يتناول الإطار النظري التعلم التعاوني الذي يساعد على تكوين اتجاهات إيجابية نحو الخبرات التعليمية، وتحقيق الذات الذي يعتبر مؤشراً هاماً من مؤشرات الصحة النفسية، وذلك على النحو التالي:

ولاً: التعلم التعاوني: هو طريقة حديثة في التعليم تبتعد في أسلوبها عن الطرق التقليدية، كاللوح والطبشورة، حيث أَّها تستخدم طريقة التشارك بين الطلاب في النقاش، فيجلسون بشكلٍ دائري ويعرض كل طالب أفكارهُ ووجهة نظره للجميع حتى يستفيد كل فرد من الآخر في التفكير والوصول للحلول. (عادل

محمد، 14014: 14014)

فو ائد التعلم التعاوني: يرى عبادة الخولي (1997: 27) أن هذه طريقة من التعلم تخفف على الطلاب الرهبة من الدراسة والخوف من طريقة التعليم التقليدية التي ينفرد بها المعلم في التفكير، كما أنها تساعد على تبادل الأفكار بين الطلاب ومعرفة جميع وجهات النظر التي تؤدّي إلى اكتشاف حلول ونتائج جديدة ومهمة. كما يضيف (Brandt, Ellsworth, 2011:15) أنه من فوائد التعلم التعاوني ما يلي: تعزيزُ روح التعاون لدى الأفراد، وإثارةٌ جو المرح الذي يعطي الراحة للطالب. اتاحة الفرصة لكل طالب بأن يسأل زملاءه ويستعين بهم بدلاً من المعلم عندما يحتاج لذلك. طريقة التعلم التعاوني تستخدم أيضاً في مجالات عديدة ليس فقط التدريس، وتعدّ من أهم الطرق في العلاج النفسي الجماعي فيستمع المرضى لبعضهم البعض ويطرح كل مريض حل لمشكلة الآخر. شروط التعلم التعاوني: من شروط التعلم التعاوني ما يلي (Lee luck,2015:126): أن تتكوّن المجموعة من (4) أفراد أو (6) على الأكثر، على ألّا تكون أكثر من ذلك؛ حتّى لا يؤثر على تركيز المجموعة ويشتّهمه. لا يعتمد كل من الطلبة على الآخر؛ فهذه الطريقة تقوم على التعاون فيما بينهم والعمل الجماعي. 
أن يكون المعلم مرجعاً للطلاب في كل الأوقات فيسألوه بما لا يعرفوه.

كما يذكر (Davidson, 2006:201) من شروط التعلم التعاوني التالي:

أن يتناقش الطلاب مع بعضهم البعض، وأن يأخذ كل فرد في المجموعة برأي الفرد الآخر دون الحياد عن المجموعة، أو أن يعتبر أي فرد نفسه مستقلاً عن الآخر.

الانضباط وعدم استغلال الوقت المعطى للمجموعة في اللهو، يجب أن يلتزم كل طالب في المناقشة وعدم التكلم بلا فائدة.

خطوات تطبيق التعلم التعاوني:

يسير التعلم التعاوني بعدة خطوات منها (Jocobs, etal, 2011: 196; Johnson, Johnson\& Smith, 2000:88) أن يحدّد المعلم أفراد المجموعة التي تتكوّن من 6 أفراد على الأكثر. يعطي لكل فرد من أفراد المجموعة رقماً يُعرّف باه. تسمّى كل مجموعة باسمٍٍ محدد أو تعطى لقباً لمعرفتها.

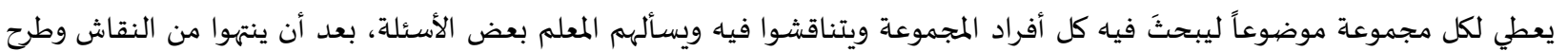
الأفكار فيما بينهم. يحدّد المعلم فرداً في المجموعاة يمثلها ويتكلم بالنيابة عنها، ولكن في بعض الأحيان يفضل المعلم أن يتكلم جميع الأفراد ويشاركوا في الحديث

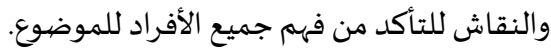
بعد الانتهاء من النقاش مع جميع أفراد المجموعة يطلب المعلم مدونة بالأسئلة التي طرحت عليهم مع إجاباتها. يجب أن يحدّد المعلم مدى نجاحاه في تحقيق الأهداف المرجوة ،من تشكيل المجموعات لتطبيق طريقة التعلم التعاوني. تعدّ طريقة التعلم التعاوني من أنجح الطرق على الإطلاق خاصةًً في المواد التي تحتاج إلى الكثير من المناقشة والتواصل بـاصل بين المعلم والطلبة، فهذه

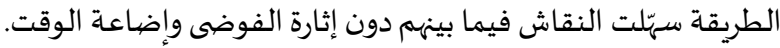
ثانياً: تحقيق الذات: هي عملية تنمية قدرات ومواهب الذات الإنسـانية وفهم الفرد لذاته وتقبلها مما يساعد على تحقيق الاتساق والتكامل والتناغم ما بين مقومات الشخصية وتحقيق التوافق بين الدوافع والحاجات والناتج من ذلك. (زبيدة امزيان ، 2007: 24)

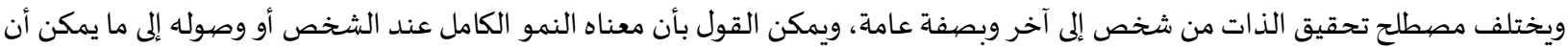

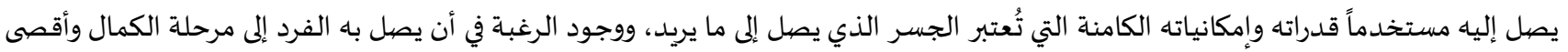

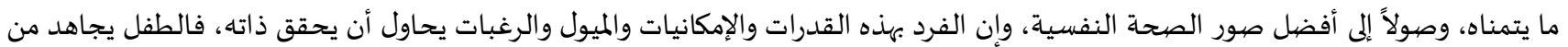
السن المبكرة جداً وبشتى أنواع المحاولات ليجعل من نفسـه الشخص الذي سيصبحهاه في المستقبل. خصيائص الأفراد المحققين لذاتهم:

يحدد "ماسلو" خصائص الأفراد المحققين لذاتهم في الآتي (2017, Cer \&sahin): لديهم منظور أكثر فاعلية للواقع: يُمكنهم هذا المنظور من إدراك العالم من حولهم بطريقة سليمة وفعالة، فهم يرون الحقيقة كما هي وليس كما يُأملون. تقبل الذات والآخرين والطبيعة: فهم لا ينهمكون في نقد عيوبهم وفشلهم وضعفهم، ولا يحملون أنفسهم مشاعر ذنب وخزي وقلق، بل يشعرون بالرضا عن أنفسهم ويتقبلون طبيعتهم الإنسانية، ويتقبلون الناس من حولهمه مركزية المشكلة: يرتبطون بالواجب نحو المجتمع، فهم لا يتمركزون حول ذواتهم فهم يعملون من خلال إطار مرجعي ويستطيعون التفرقة بين ما هو مهم وما هو غير مهمى الاستقلال الذاتي عن الثقافة والبيئة: فهم يتحملون المسؤولية ولديهم القدرة على ضبط وتوجياء الذات والقدرة على التحكم فيها. التجديد المستمر في تقدير الأشياء: لديهم القدرة على تقييم الأحداث العادية في حياتهم بشعور من التجديد والمتعة، فخبراتهم الذاتية وعملهم اليومي مصدر متعقة وشوق لا ينقطع. الخبرات الغامضاة أو بالغة الذروة: حيث يأتون باكتشافاتٍ غير متوقعة يعيشون لحظات من الإثارة الشديدة والتوتر العالي يعقها هدوء واسترخاء بالمعرفة وتقديم الجديد. الاهتمام الاجتماعي: يميلون إلى علاقات شخصية أكثر عمقاً مع الآخرين من علاقات الأفراد العاديين، ويتسمون بقدرة على التعاطف مع الآخرين. 
ه التمييز بين الوسائل والغايات: فهم يميزون بين الوسائل التي تستخدم لتحقيق الغايات وفي كثير من الأحيان يستمتعون بتلك الوسائل لذاتها دون السعي إلى تحقيق أهداف ورائها.

الحس الفلسفي للدعابة: يتمتع محققو الذات بقدرة على إطلاق الدعابة والنكات، إلا أن الدعابة لديهم تثير مشكلة أو توصل لهدف خله خلفها أو تعالج مغزى ما.

الإبداع: فهم مبدعون واعتبر ماسلو أن الإبداع صيميم وجود الإنسان.

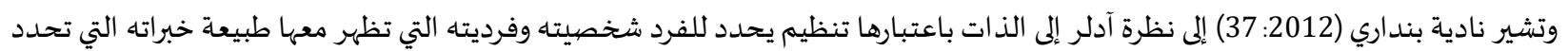
له أسلوبه المتميز في الحياة، ولما كانت الذات هي مركز الشخصية التي تتجمع حولها كل النظم الأخرى وهي التي تمد الشخصية بالتوازن والثبات؛ فإن إن الثران

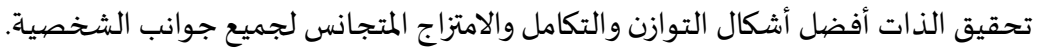
ويؤكد طلعت منصهور؛ وفيولا الببلاوي (2005) أن تحقيق الذات هو غاية الصحة النفسية أو الشخصية السوية، كما أنها يمكن النظر إلى نموذج الشخص المحقق لذاته على أنه غاية الإرشاد والعلاج النفسي وذلك باعتباره شخصاً يقوم بتحسين وتوظيف ولتون طاقاته. ويشير عبد اللطيف النعيم (2010: 271) أن ماسلو صاحب مصطلح تحقيق الذات وصايهاحب الإنب النظرية القائمة على افتراض أن جميع الأفراد هم

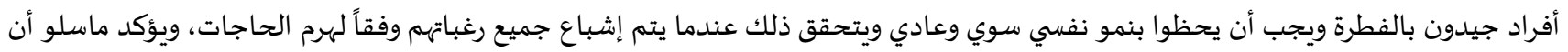

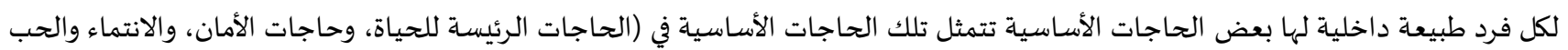

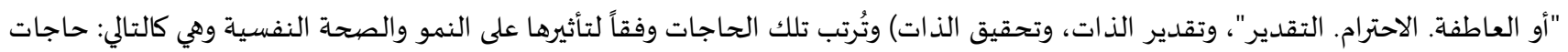

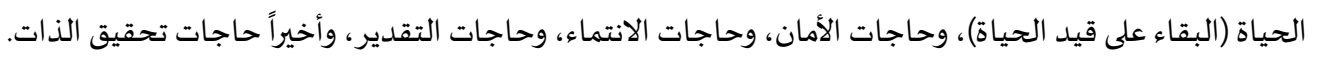

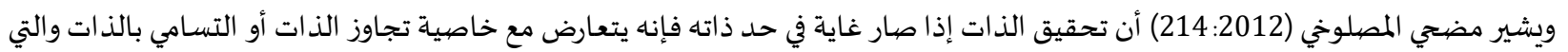

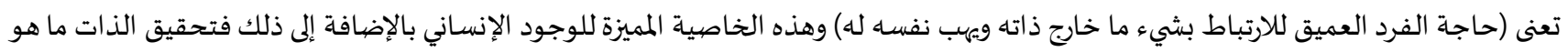
إلا نتيجة أو أثر أي نتيجة أو أثر لتحقيق المعنى وينبغي أن يظل تحقيق الذياء الذات هكذا، وذات وذلك لأن الإنسان لا يحقق ذاته إلا بقدر تحقيقه لمعنى في هذا

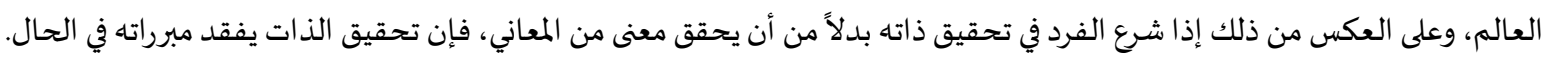

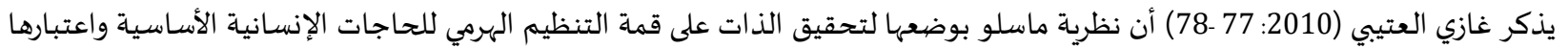
للأشخاص المحققين لذواتهم بأههم هم الذين يتمتعون بمقومات السلامة النفسية فهي بحاجة إلى توسيع وتعميق وتأصيل لمفهوم تحقيق الذات،

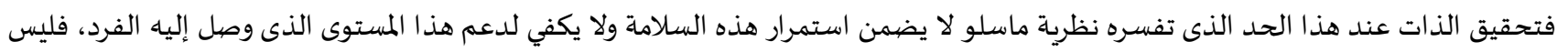
المهم أن تصل إلى القمة ولكن المهم أن تحتفظ بها، ولعل هذا يؤول بنا إلى أن نؤكد جانباً أخر في تحقيق الذات الذات نحاول باء توسيع وتعميق وتأصيل مفهومها

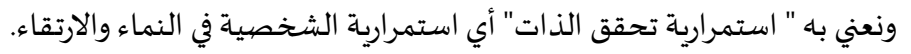

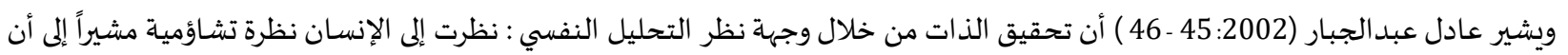

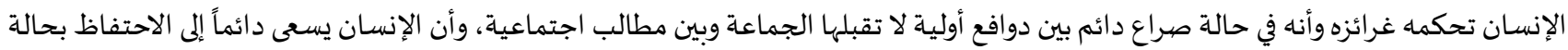

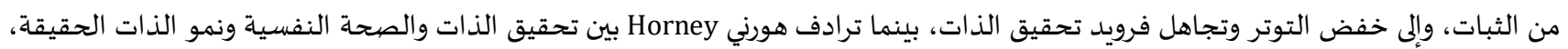

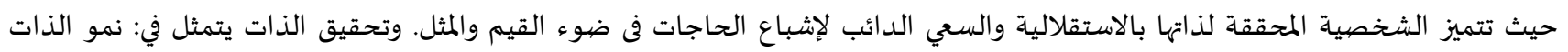

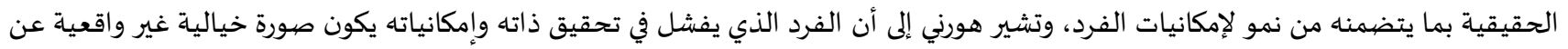

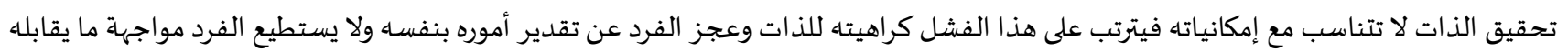
من صعوبات. يشير صالح الشعراوي (2011: 27) تحقيق الذات من خلال وجهة النظر السلوكية، أن فرويد ركز على الغرائز ودورها في تحريك السلوك الإنسـاني

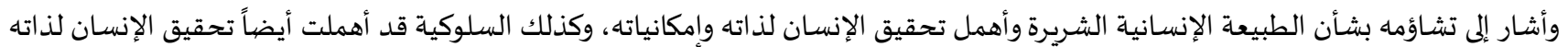

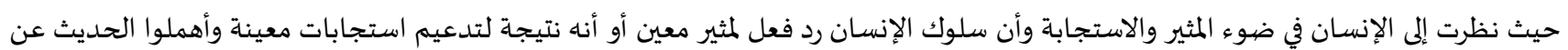

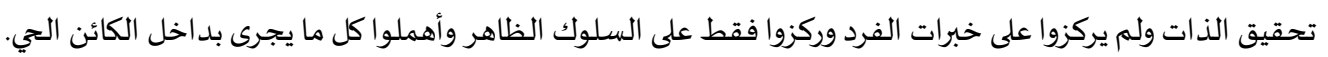

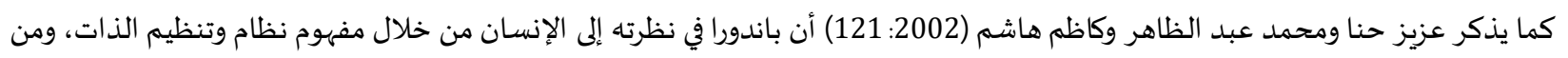

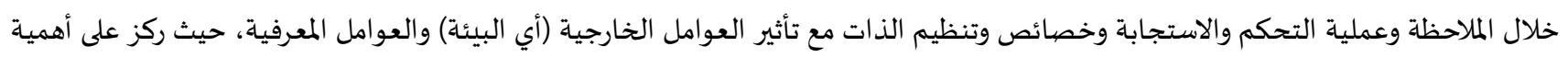

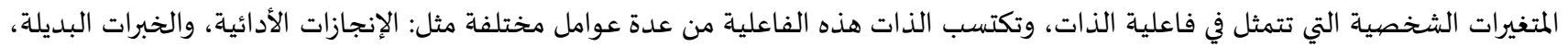

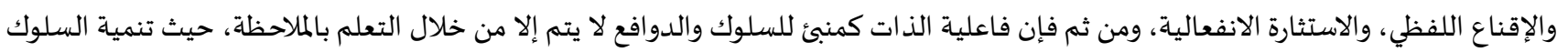

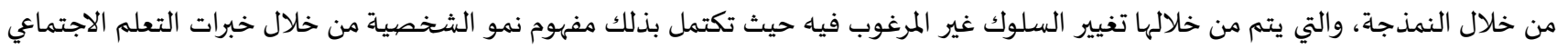

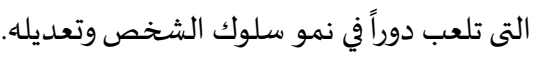


يوضح لويس مليكة (2001 : 97 ـ 98) تحقيق الذات من خلال وجهة نظر الاتجاه الإنساني، أن المذاهب الإنسانية ترتبط في علم النفس عامة

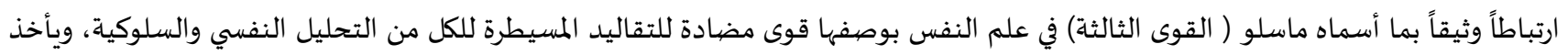

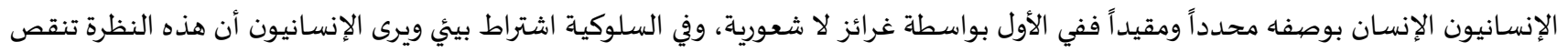

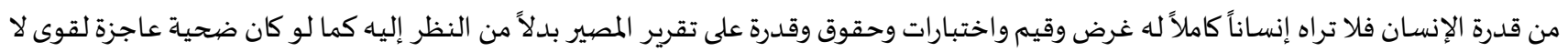

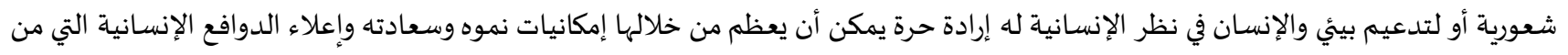

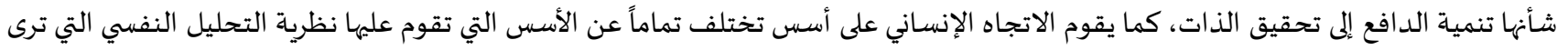

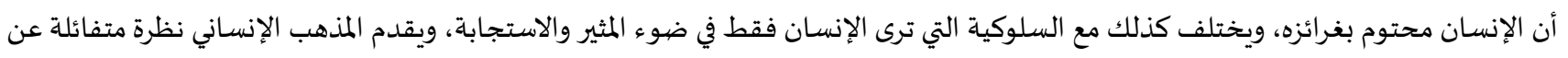

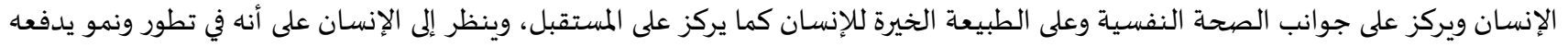

دائماً لتحقيق ذاته.

الدراسات السابقة:

نظراً لندرة الدراسات التي جمعت بين متغيري الدراسة (التعلم التعاوني - تحقيق الذات) - في حدود علم الباحثة - تناولت الباحثة الدراسات القريبة إلى متغيري الدراسة على النحو التالي:

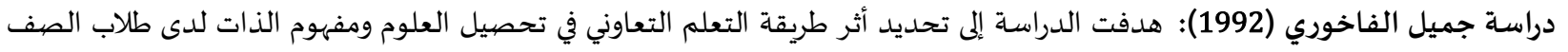

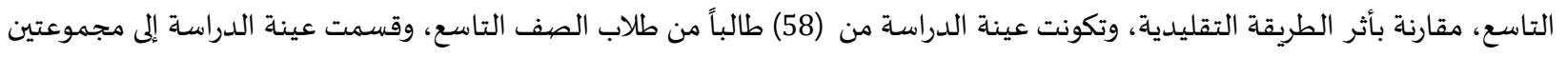

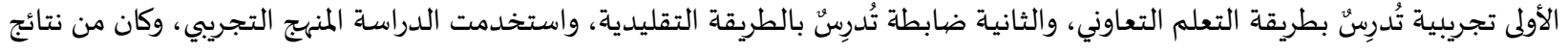

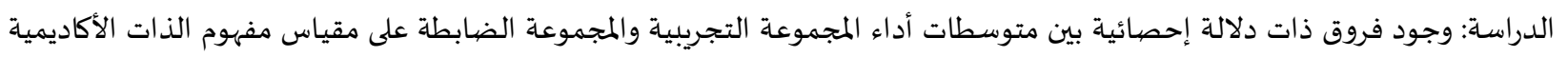
لصالح المجموعة التجريبية، في حين لم توجد فروق ذات دلالالة إحصائية بين متوسط أداء المجموعتين على مقياس مفهوم الذات النفسية والجسيمة والاجتماعية. دراسة (Punch \& Baverly,1997) هدفت التعرف إلى تأثيرات بيئات التعلم التعاوني والتنافسي والفردي على السلوك وفعالية الذات والتحصيل

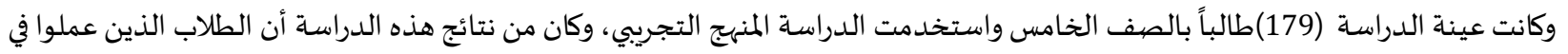

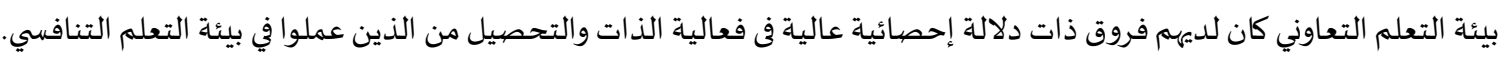

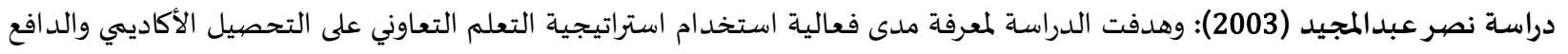

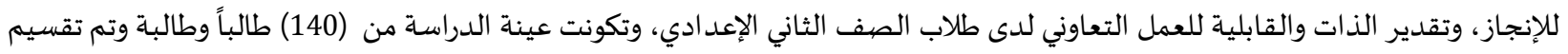

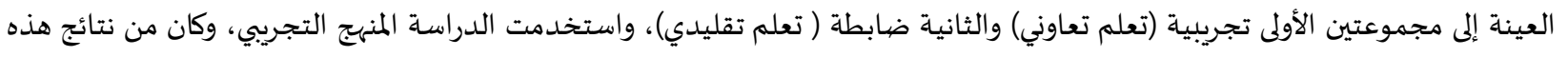

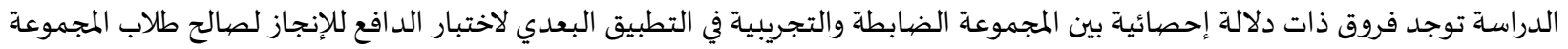

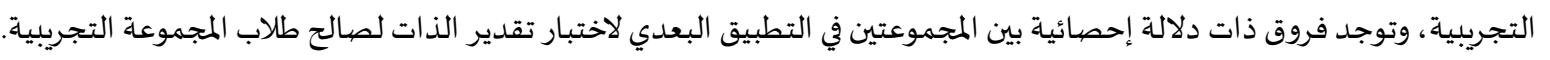
دراسة (Nichols \& Miller,2007) وهدفت هذه الدراسة إلى معرفة تأثير التعلم التعاوني الجماعي على التحصيل والتوجاه نحو الهدف وفعالية

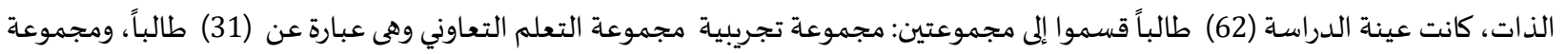

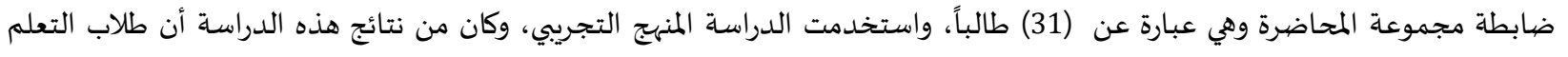

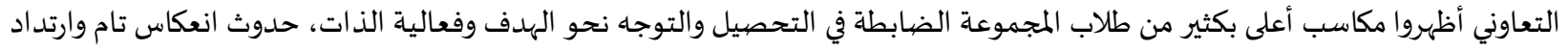

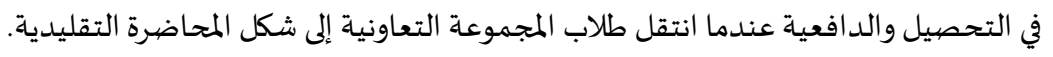

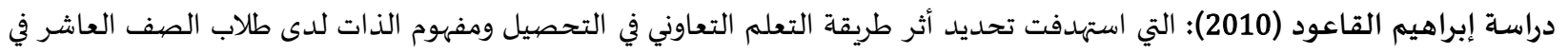

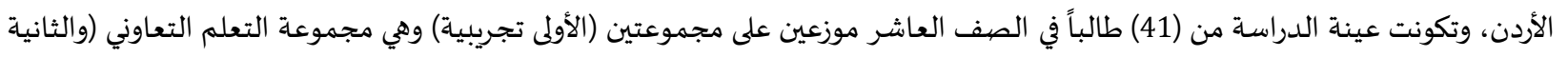

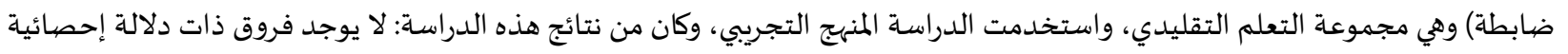

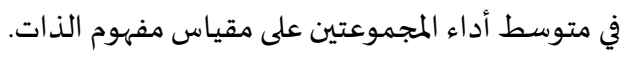

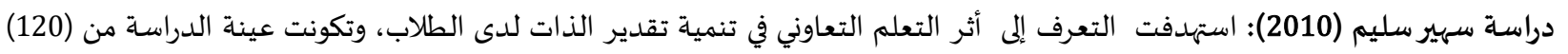

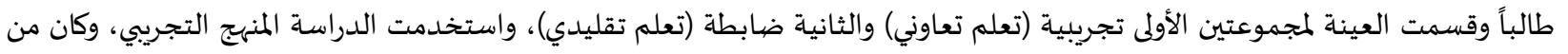

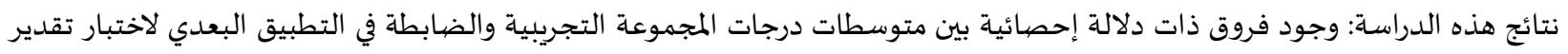
الذات لصالج المجموعة التجريبية، كما وجدت فروق بين التطبيق القبلي والبعدي لاختبار تقدير الذات في المجمموعة التجريبية لصالح التطبيق 
هراسة عادل شوشان (2013): هدفت الدراسة التعرف إلى أثر برنامج قائم على التعلم التعاوني في تنمية مهارات التفكير وفاعلية الذات

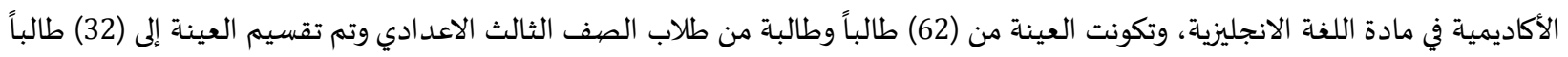

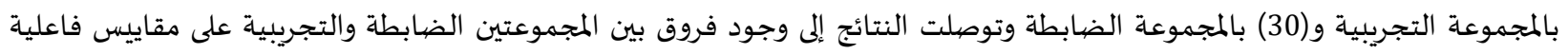

الذات الأكاديمية وتنمية التفكير لصالح المجموعة التجريبية.

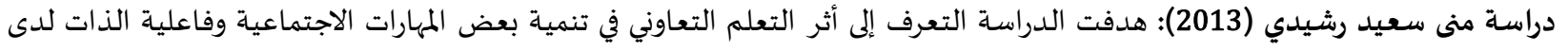

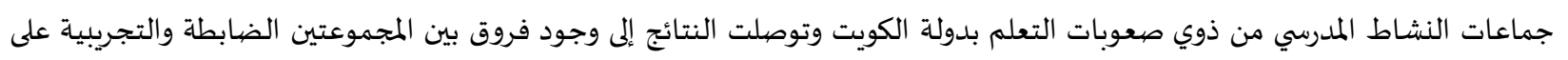
مقاييس فاعلية الذات لصالح المجموعة التجريبية.

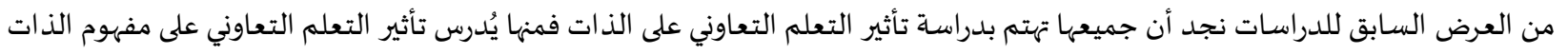

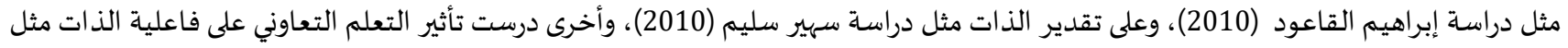

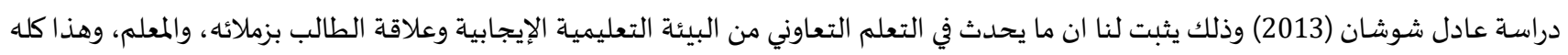

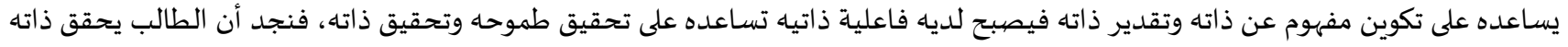

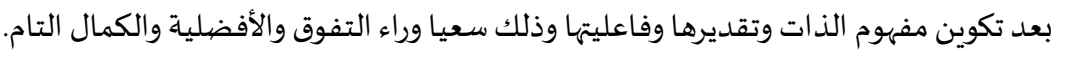

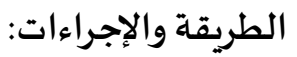

منهج الدراسة:

استخدمت الدراسة المنهج التجريبي وهو المنهنج الملائم لطبيعة الدراسة.

مجتمع الدراسة:

تكون مجتمع الدراسة من جميع طلاب الصف الثالث الثانوي بمدينة بنها والمقدر عددهم ب (520) طالباً. تراوحت أعمارهم من (16-18) سنة، وجميعهم من الاقسام العلمية والأقسام الأدبية.

عينة الدراسة:

تكونت عينة الدراسة من عينة قوامها (60) طالب من طلاب الصف الثالث الثانوي بمدرسة بنها الثانوية، تراوحت أعمارهم بين (16 -18) عام.

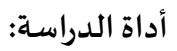

قامت الباحثة بإعداد مقياس تحقيق الذات لطلاب المرحلة الثانوية، كأداة للدراسة، حيث قامت بمراجعة الإطار النظري المتعلق بالموضوع، كما

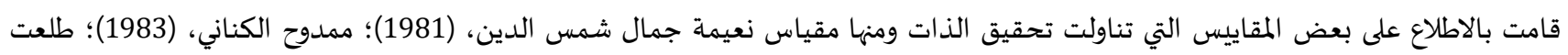

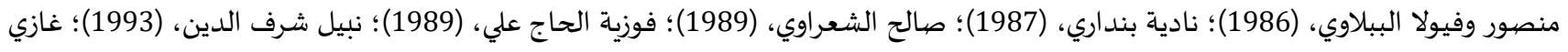

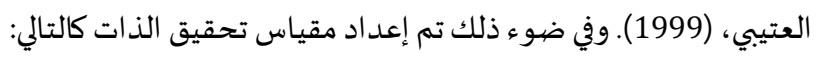

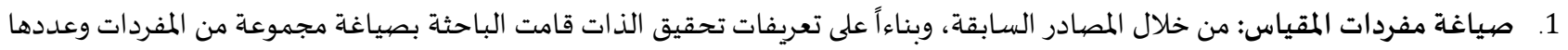

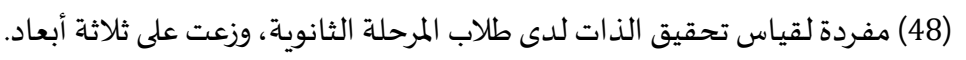

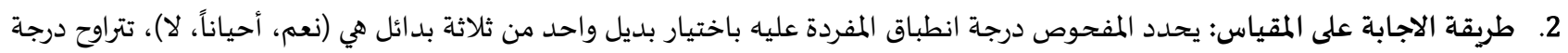

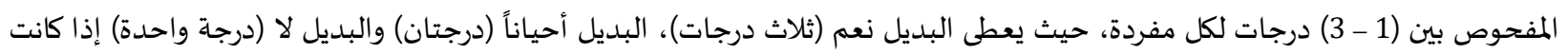

المفردة موجبة وبالعكس إذا كانت المفردة سالبة. الخصائص السيكو مترية لمقياس تحقيق الذات:

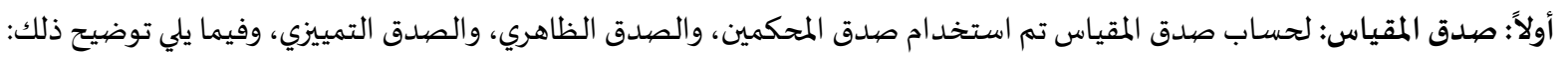

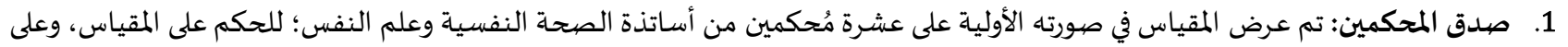

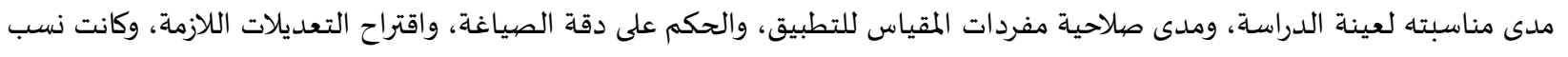
اتفاق السادة المحكمين على عبارات مقياس تحقيق الذات، لا تقل عن (80\%) في جميع العبارات، وبالتالي لم تستبعد الباحثة أية عبارة من عبارات المقياس. 2. الصدق الظاهري: قامت الباحثة بتطبيق مقياس تحقيق الذات على عينة التقنين، والتي بلغ قوامُها (80) طالباً من طلاب المرحلة الثانوية، تتراوح

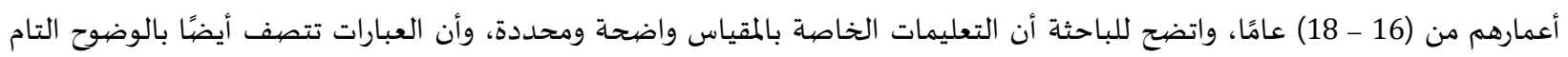

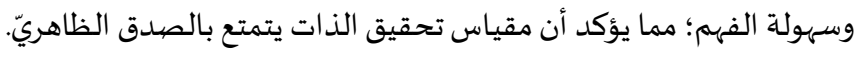


3. الصيدق التمييزي (صيدق المقارنة الطرفية): قامت الباحثة بحساب الصدق التمييزي (صدق المقارنة الطرفية)؛ وذلك للتحقق من القدرة

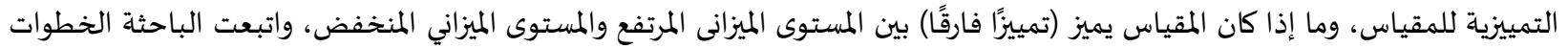

الآتية لحساب الصيدق التمييزي:

ترتيب درجات أفراد العينة الاستطلاعية وعددهم (80) فردًا ترتيباً تنازلياً.

تحديد 27\% من العدد الكلى للدرجات من أول الترتيب التنازلي ومن آخره، أي تم تحديد أول (22) فردًا من الترتيب كأفراد للمستوى الميزاني

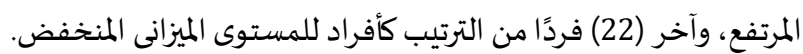

حساب الفرق بين متوسطات درجات الأفراد في مُستويّ الميزانيين عن طريق استخدام الإحصاء البارامتري، والمتمثل في اختبار "ت" للدلالة

الإحصائية للعينتين المستقلتين، والجدول الآتي يوضيح نتائج هذا الإجراء:

\begin{tabular}{|c|c|c|c|c|c|c|}
\hline $\begin{array}{c}\text { الدلالة } \\
\text { sig }\end{array}$ & قيمة & الحربة & المعراف & المتوسط & المجموعة & مقياس تحقيق الذات \\
\hline دالة عند 0,01 & 18,783 & 42 & $\begin{array}{l}1,677 \\
2,672\end{array}$ & $\begin{array}{c}34,636 \\
22\end{array}$ & المستوى المنخفض المرتفع & الثقة بالنفس \\
\hline دالة عند 0,01 & 22 & 42 & $\begin{array}{l}0,972 \\
2,667\end{array}$ & $\begin{array}{l}34,772 \\
21,454\end{array}$ & المستوى المنخفض المرتفع & التفاؤل \\
\hline دالة عند 0,01 & 16,485 & 42 & $\begin{array}{l}1,617 \\
2,873\end{array}$ & $\begin{array}{l}34,045 \\
22,454\end{array}$ & المستوى المنخفضض المرتفع & فاعلية الذات \\
\hline دالة عند 0,01 & 14,584 & 42 & $\begin{array}{l}4,847 \\
1,641 \\
\end{array}$ & $\begin{array}{l}33,290 \\
33,863 \\
\end{array}$ & المستوى المنخفض المرتفع & القدرة على الإنجاز \\
\hline دالة عند 0,01 & 25,644 & 42 & $\begin{array}{l}1,715 \\
9,101\end{array}$ & $\begin{array}{c}138,090 \\
87,454\end{array}$ & المستوى المنتخفض & الدرجة الكلية \\
\hline
\end{tabular}

يتضح من جدول (1) أن الفرق بين الميزانين المرتفع والمنخفض في جميع الأبعاد والدرجة الكلية دال إحصائياً عند مستوى (0.01) وفى اتجاه

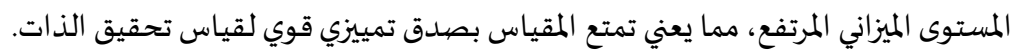

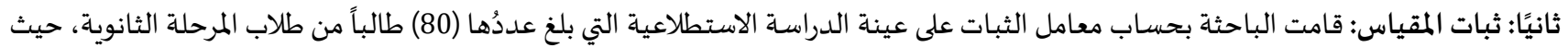

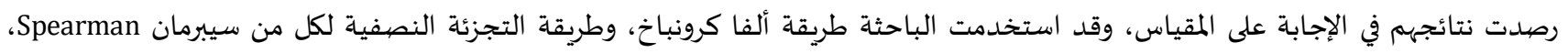

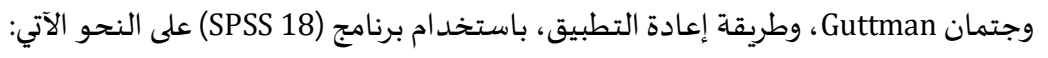

1

تم حساب معامل الثبات للمقياس باستخدام معامل ألفا كرونباخ (Cronbach's Alpha)، باستخدام برنامج التحليل الإحصائي للبيانات

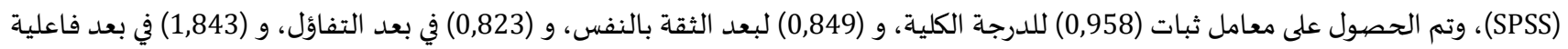

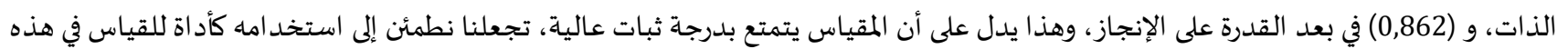

2.

تعمل تلك الطريقة على حساب معامل الارتباط بين درجات نصفي مقياس تحقيق الذات، حيث تَمَّ تجزئة المقياس إلى نصفين متكافئين، يتضمن

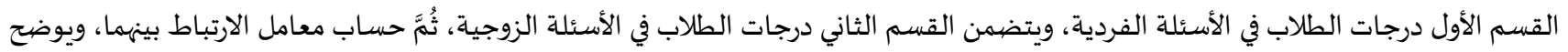

الجدول الآتي الثبات بطريقة التجزئة النصفياة:

\begin{tabular}{|c|c|c|c|c|c|}
\hline \multicolumn{6}{|c|}{ جدول (2): الثبات بطريقة التجزئة النصفية للمقياس } \\
\hline م & معامل سبيرمان & معامل & معامل ألفا & ull & 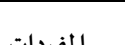 \\
\hline معامل المبات لبجمال & براون & 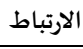 & 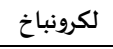 & التعدد & المحردات \\
\hline \multirow{2}{*}{0,850} & \multirow{2}{*}{0,862} & \multirow{2}{*}{0,757} & 0,946 & 24 & الجزء الأول \\
\hline & & & 0,910 & 24 & الجزء \\
\hline
\end{tabular}

يتضح من جدول (2) أن معامل ثبات مقياس تحقيق الذات يساوي (0,862)، وهو معامل ثبات يشير إلى أن المقياس على درجة عالية من الثبات،

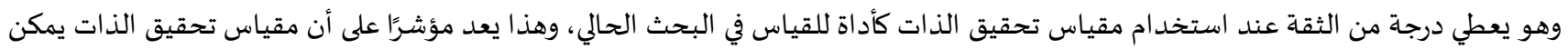
أن يعطي النتائج نفسها إذا ما أعيد تطبيقه على العينة وفى ظروف التطبيق نفسها. 
3. طريقة إعادة التطبيق:

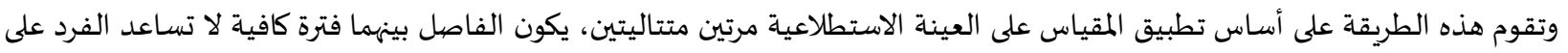

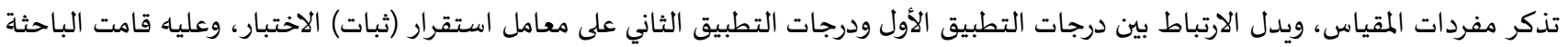

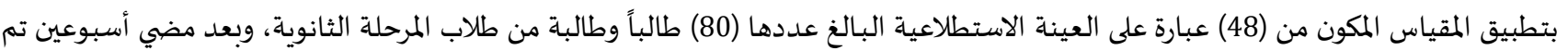

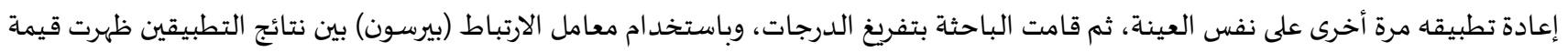

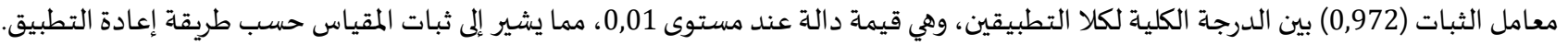

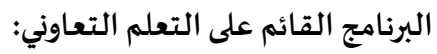

تم تصميم البرنامج القائم على التعلم التعاوني في مقرر الأحياء الصفف الثالث الثانوي (تخصص علمئ علئ علوم) وفقاً للخطوات التالية:

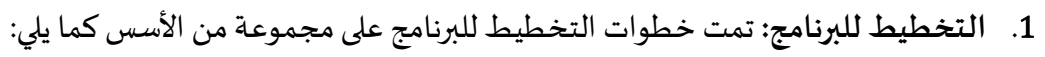

أ. تحديد الأهد اف للبرنامج (أهداف عامة - أهداف إجرائية).

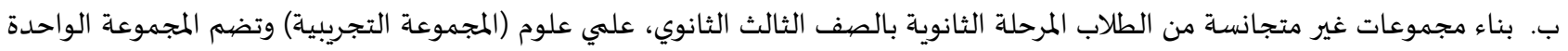
(5) أفراد، ويعطى اسم لكل مجموعة يستمر معها طوال جلسات البرنامج.

ج. تحديد دور كل طالب في المجموعة (قائد - قارئ - مستوضح - ميقاتي- مقرر) بالإضافة إلى المهمة التي ينجزها في في إتمام النشاط. د. تحديد أسـاليب التقييم (أداء الفرد داخل الجماعة - أداء المجموعة ضمن المجمموعات- التقييم من خلال التقرير الذاتي للطلاب) هـ تحديد معايير النجاح والإنجاز الفردي والجمائي.

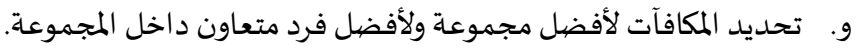

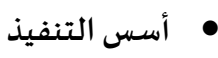

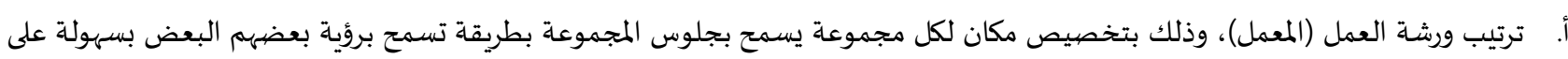

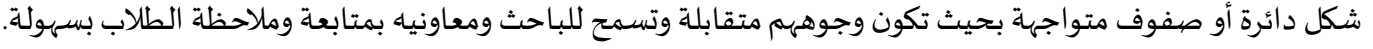

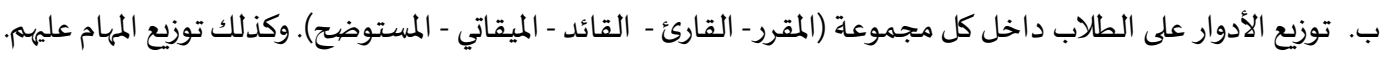

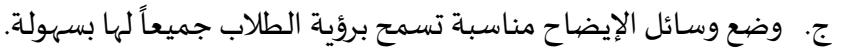

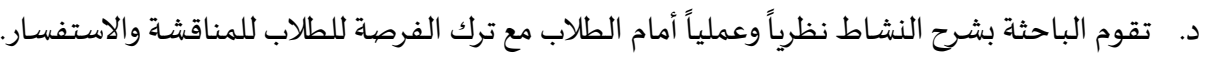
هـ تقوم الباحثة بتوجياء المجموعات إذا لزم الأمر أثناء قيامهم بالنشاط مع تدوين ملاحظاته في بطاقات ملاحظاته للطابلاب، وبطاقات تقييم أداء كل مجموعة في أنشطة البرنامج. أسس التقييم: تححديد المجموعة الأفضل من خلال تقييم المجموعات وتحديد أفضل طالب متعاون بكل مجموعة في ضوء بنود بطاقتي الملاحظة الخاصة بتقييم أداء الطالب وأداء المجموعة. ب. تقديم المكافآت لأفضل مجموعة ولأفضل طاء المبوعه الب متعاون.

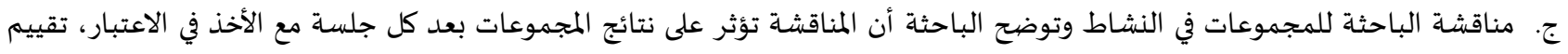

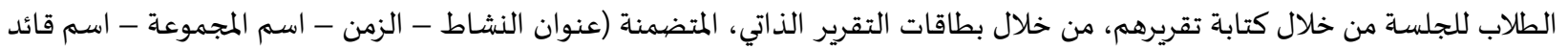
المجموعة - عدد أعضاء المجموعة - أسماء أعضاء المجموعة والمهام الموكلة لكل عضو - خطوات إنهات إجراء وتنفيذ النشاط - الصعوبات والعقبات التي واجهت المجموعة في العمل معاً - المقترحات التي يراها الطلاب لتحسين الأداء في المرات القادمة). 2. تنمية التفاعل بين الطالب المراهق وزملائه وبين الطالب والمعلم. تحقيق الاعتماد الإيجابي المتبادل بين الطلاب المراهقين بالمرحلة الثانوية. إكساب الطلاب المراهقين بالمرحلة الثانوية مهارات التفاعل الاجتماعي مثل: التعاون واحترام رأي الغير، والبعد عن الذاتية، وعدم التحيز للآراء

الشخصية.

مساعدة الطالب على تكوين نظرة إيجابية عن ذاته. مساعدة الطالب لتحقيق أعلى مستوى إنجاز وتحقيق التقدم والتفوق. 
مساعدة الطالب على التحكم في البيئة من خلال التخطيط لأي عمل واتخاذ القرارات لمسايرة البيئة بما يتناسب معه. مساعدة الطالب لاكتساب بعض الخصائص لتنمية تحقيق الذات لدياه مثل إدراكه للواقع، وتقبل الذات وتقبل الآخرين، التوحد مع الناس وتحسين العلاقات مع الآخرين.

إتاحة الفرصة أمام الطالب للتعبير عن رأيه بحرية لتنمية تحقيق الذات لديه وجعله يشعر بالتفاؤل والرضا عن النفس والثقة بها.

3.

الحدود الزمنية: تم تنفذ البرنامج على مدى (8) أسابيع بمعدل (2 : 4) جلسات أسبوعياً تبعاً لنوع النشاط، حيث تستغرق كل جلسة (أ) في كل

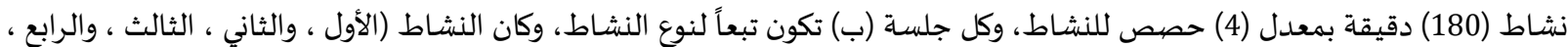
والخامس) 180 دقيقة بمعدل (4) حصص للنشاط، والنشاط (السـادس ، والسابع ، والثامن) 540 دقيقة بمعدل (12) حصية على ثلاثة أيام

متتالية.

الحدود المكانية: تم تنفيذ البرنامج في ورش العمل (معمل الأحياء) بمدرسة بنها الثانوية. هالحدود البشرية: تم تطبيق البرنامج على (30) طالباً، ممن يمارسون الأنشطة المعملية المقررة. 4. الأنشطة التي بني علهها البرنامج:

من خلال المحتوى الدراسي لمادة الأحياء بالصف الثالث الثانوي (تخصص علمي علوم) قامت الباحثة بتحليل المحتوى لمجموعة من الأنشطة

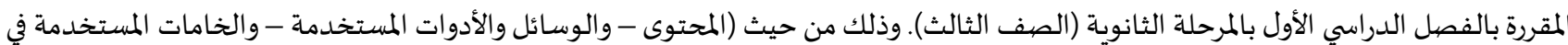

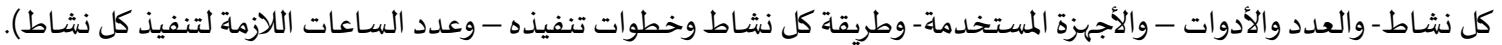
5. دور المعلم:

أ. إعداد مصيادر التعلم والأدوات والوسائل اللازمة للمجموعات. ب. تقسيم المجموعات وكل مجموعة تضم (5) أفراد وكل مجموعة لها اسمها المعروفة به طوال جلسات البرنامج مع تحديد وقت إنجاز المهمة. ج. تحديد دور كل طالب بالمجموعة وتحديد مهمتاه في النشاط.

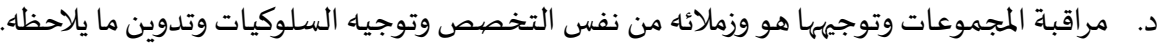

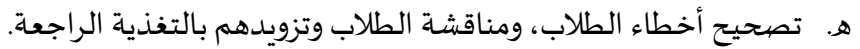
و. تذليل العقبات التي تواجه الطلاب وحثهم على التقدم لإنجاز المهام التعاونية وإتمام النشاطهاط. ز. عرض المفاهيم الجديدة وتوضيح الغامض منها على الطلاب. ح. تقييم أداء الطلاب والمجموعات ومقارنة الأداء للمجمموعات للوصول لأفضل مجموعة وأفضل طالب متعاون، ومكافأة أفضل مجموعة وأفضل طالب متعاون بكل مجموعة. دور الطالب:

أ. استلام أوراق العمل الخاصة بالنشاط والأدوات والوسائل اللازمة لإتمام مهام النشاط.

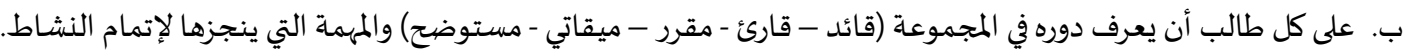
ج. مساعدة زملائه أثناء المناقشة وأثناء التنفيذ للنشاط. 6. الأساليب المستخدمة في التعلم التعاوني:

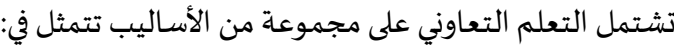
أسلوب المحاضرة: وفياه وضحت الباحثة أهمية التعلم التعاوني وأهمية البرنامج وما يحتويه من أنشطة في تعليم الطلاب في المدرسة بالمرحلة الثانوية أو في حياتهم الاجتماعية والعملية. ويشرح المعلم عن طريق المحاضرة المعلومات الجديدة وعلى الطلاب. أسلوب المناقشة والحوار: وتدور بين الطلاب والمعلم وبين الطلاب وبعضهم البعض والتي تتم في صورة الأسئلة التمهيدية التي تقدمها الباحثة قبل إجراء النشاط، والمناقشات التي تتم قبل وأثناء وبعد تنفيذ النشاط ومناقشة المشكلات والعقبات التي تواجهينهم قبل وأثباء وأثناء التنفيذ. أسلوب العمل والتنفيذ: تكلف الباحثة الطلاب بالمهام التعاونية وتقوم كل مجموعة بالتعاون بين أعضائها فى إنجاز النشاط طبقاً لما شاهدوه من قِبَلِ الباحثة في تنفيذ النشاط خطوةً بخطوة أمام الطلاب قبل أن يقوموا بالتنفيذ، ومناقشة كل خطوة مع الطلاب. ثم تكلف الطلاب في كل مجموعة بكتابة تقرير بعد كل جلسة، وهو عبارة عن تقييم الطلاب للجلسة متضمناً (عنوان النشاط، الزمن، اسم

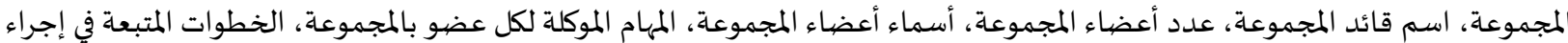


تنفيذ النشاط، العقبات التي واجهت المجموعة أثناء العمل معاً في تنفيذ النشاط، المقترحات التي يراها أفراد كل مجموعة لزيادة كفاءة أفرادها في المرات القادمة).

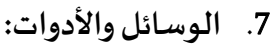

تختلف الوسائل وتتعدد تبعاً لاختلاف المهام التي يكلف بها الطلاب في كل نشاط. وقد راعت البات الباحثة في هذه الوسائل والأدوات ما يلي:

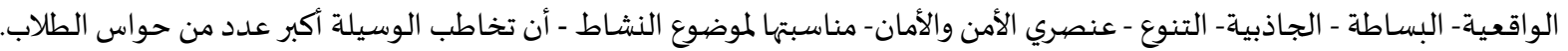
ومن الوسائل والأدوات والخامات التي تستخدمها الباحثة: بطاقات أوراق العمل الخاصية بكل نشاطي، السبورة وملحقاتها (طباشير ألوان - ممحاة)،

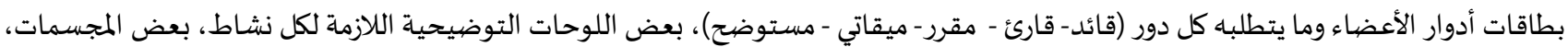
لوحات ورق لرسم النشاط . أو كراسات اسكتش ، وأقلام رصاص وأطقم المثلثات (30-60) و و (45) . 8.

تحديد أهداف الجلسة: تحديد الأهداف العامة والخاصة المرجوة من كل نشاط وذلك في صورة سلوكية. تنظيم المجموعات: تقسم الباحثة الطلاب إلى مجموعات. وذلك بترك الفرصة للطلاب لاختيار بعضهم البعض حتى يتوفر الانسجام والجو النفسي اللائق للعمل على أن يكون عدد أعضاء المجموعة (5) أفراد وأن تأخذ كل مجموعة اسم تعرف باه طوال جلسات البرنامج وإعطاء كل طالب بكل مجموعة رقم وهو نفس الرقم للكرسي الذي يجلس عليها. تنسيق المقاعد: تبدأ كل مجموعة في تنسيق مقاعدها بطريقة تسمح لأعضاء كل مجموعة برؤية بعضهم البعض بصورة واضحة تسمح للباحث

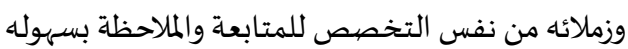
توزيع الأدوار: تحدد الباحثة دور كل عضو في المجموعة، بحيث يكون لكل مجموعة (قائد- قارئ - مستوضح- مقرر - ميقاتي)، توزع عليهم بطاقات بالدور وما يتطلبه ذلك الدور. مع مراعاة أن كل فرد بالمجموعة سيلعب دوراً مختلف في كل جلسة عن الدور السابق له في الجلسـة السابقة، بحيث

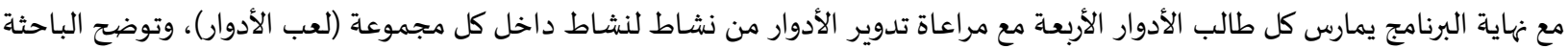
مهام كل دور كالتالي: أ. يتمثل دور القائد في: تنظيم العمل داخل المجموعة بحيث يشارك جميع أفرادها في النشاط وفي المناقشة، ومنح كل عضيو من أعضاء المجموعة

$$
\text { فرصة للحديث وعدم السماح لأحد باحتكار الجلسـة. }
$$

ب. يتمثل دور القارئ في: قراءة التكليفات بصوت مرتفع أمام الجميع، وكذلك قراءة النتائج التي تم التوصل إليها من قبل المجموعة.

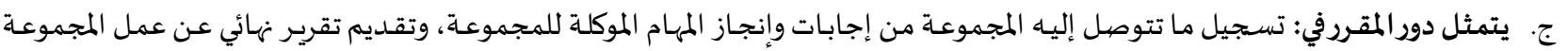
المشترك فياء كل أعضاء المجموعة متضمناً العديد من النقاط المشـار إليها مسبقاً وأهمها وخطوات النشاط والعقبات التي واجهت المجموعاة في

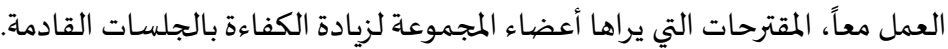
د. يتمثل دور المستوضح في: التأكد من فهم كل عضو بالمجموعة لإجراءات وخطوات النشاط، وطلب المزيد من الشرح أو التوضيح أو إعطاء أمثله تزيد من فهم أعضاء المجموعة من قبل العضو المسئول عن شرح المهمة التي ينجزها، وطلب المساعدة من المعلم عند الحاجة لذلك. هـ. يتمثل دور الميقاتي في إعلام الزملاء بالمجموعة ببد اية كل مهمة ونهايتها، ومتابعة الوقت والتنبياه بعدم إضاعتهاء. 1. التمهيد للنشاط: تمهد الباحثة للنشاط بأسئلة تستثير انتباه الطلاب وتشويقهم لمعرفة موضوع النشاط. ثم تقوم الباحثة بشرح النشاط

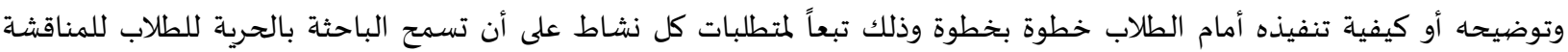
ولاستفسار أثناء أو بعد الشرح أو التنفيذ.

2. توزيع المهام وبدء العمل داخل المجموعات: بعد التأكد من فهم الطلاب لمتطلبات النشاط، تركت الباحثة فرصة للتعايش والتفاهم بين أفراد كل

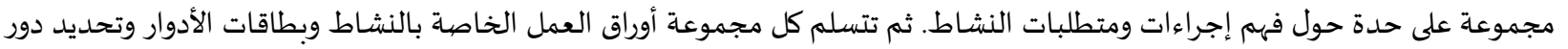

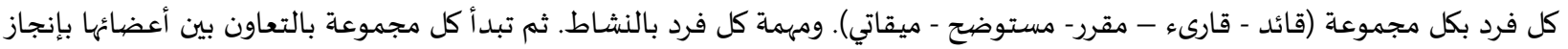

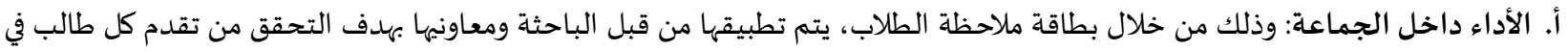
مجموعته في ضوء أسس التعلم التعاوني وتسفر هذه البطاقة عن أفضل طالب متعاون في كل مجموعة. 
ب. تقييم المجموعة ضمن المجموعات: من خلال بطاقة تقييم أداء الطلاب، بعد إجراء المناقشات قبل وأثناء وبعد التنفيذ تجمع أعمال

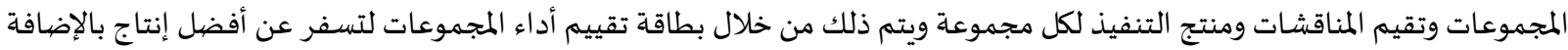

$$
\text { إلى مدى تعاون أفراد المجموعة. }
$$

$$
\text { تقييم الطلاب للجلسة وما تم فيها: }
$$

وذلك من خلال بطاقات التقرير الذاتي، حيث توزع على كل مقرر بالمجموعة بطاقات التقرير الذاتي وترك (10) دقائق، يشترك فيها كل مقرر

$$
\text { وزملائه بالمجموعة في عمل التقرير. }
$$

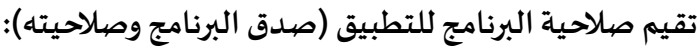

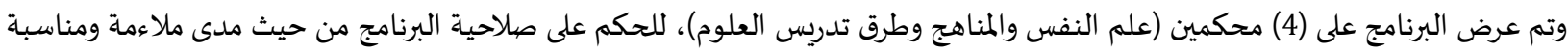
كل من الأهد اف، والمحتوى والأنشطة، والوقت المحدد لكل نشاط، ومدى ملاءمة ومناسبة الوسائل والأدوات المستخدمة، مدئ مدى ملاءمة ومناسبة طريقة

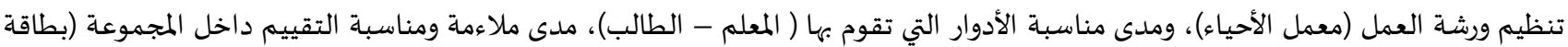

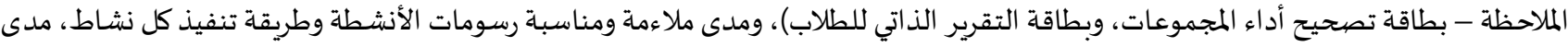
ملاءمة ومناسبة طريقة وخطوات رسم كل نشاط، طريقة وخطوات تنفيذ كل نشاط، ومدى مناسبة وسائل التقويم المتبعة في البرنامج؛ وقد أجمع المحكومون على مناسبة البرنامج وصلاحيتاه للتطبيق. خطوات تطبيق الدراسـة: 1. اختيار عينة الدراسة الحالية: وعددها (60) طالباً تراوحت أعمارهم بين (16 18) عام، وتم اختيارهم من طلاب المرحلة الثانوية بالصف الثالث

$$
\text { الثانوي (تخصص علمي علوم)، بمدرسة بنها الثانوية. }
$$

2. التصميم التجريبي: استخدمت الباحثة طريقة المجموعتين، حيث قسمت الطلاب إلى مجموعتين إحداهما تجريبية والأخرى ضابطة، مع مراعاة

$$
\text { التكافؤ بينهما ثم التطبيق القبلي لمقاييس الدراسة (تحقيق الذات) على المجموعتين. }
$$

3. تطبيق البرنامج على المجموعة التجريبية من طلاب مدرسة بنها الثانوية باستخدام التعلم التعاوني" لنتعلم معاً واستغرق ذلك ثمانية أسابيع من المنائن

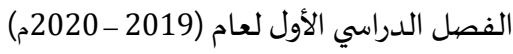

4. التطبيق البعدي: لمقياس تحقيق الذات على كل من المجموعة التجريبية والمجموعة الضيابطة، وذلك بعد الانتهاء من تطبيق برنامج التعلم

التعاوني على (المجموعة التجريبية).

5. التطبيق (التتبعي): مقياس تحقيق الذات بعد التطبيقيق البعدي بفترة زمنية (ثلاثون يوماً)، لمعرفة استمرار أثر التعلم التعاوني في تنمية تحقيق

$$
\text { الذات لدى طلاب المجموعة التجريبية. }
$$

\begin{tabular}{|c|c|c|c|c|c|c|c|c|}
\hline حجم التأثير & $\begin{array}{l}\text { قيمة } \\
\eta^{2}\end{array}$ & $\begin{array}{c}\text { الدلالة } \\
\text { sig }\end{array}$ & قيمة & درجات & الانحراف & الحسبابي المتوسط & المجموعة & ألمقياس \\
\hline 0,822 & 0,335 & دالة عند 0.01 & 14,633 & 58 & $\begin{array}{l}3,830 \\
3,738\end{array}$ & $\begin{array}{l}31,866 \\
17,566\end{array}$ & الضبابطة التجية & الثقة بالنفس \\
\hline 0,819 & 0,331 & دالة عند 0.01 & 14,379 & 58 & $\begin{array}{l}4,157 \\
3,339\end{array}$ & $\begin{array}{l}31,766 \\
17,766\end{array}$ & الضبابطة & التفاؤل \\
\hline 0,831 & 0,348 & دالة عند 0.01 & 15,494 & 58 & $\begin{array}{l}3,772 \\
3,347\end{array}$ & $\begin{array}{l}16,060 \\
31,900\end{array}$ & الضبابطة & فاعلية الذات \\
\hline 0,812 & 0,321 & دالة عند 0.01 & 13,757 & 58 & $\begin{array}{l}4,566 \\
3,510\end{array}$ & $\begin{array}{l}32,333 \\
17,866\end{array}$ & الضابطة التجية & القدرة على الإنجاز \\
\hline 0,839 & 0,359 & دالة عند 0.01 & 16,257 & 58 & $\begin{array}{l}14,929 \\
12,097\end{array}$ & $\begin{array}{c}127,866 \\
70,833\end{array}$ & التجريبية & الدرجة الكلية \\
\hline
\end{tabular}

\section{نتائج الدراسـة (مناقشتها وتفسـيرها):} النتائج المتعلقة بالإجابة عن السؤال الأول والفرض الخاص به والذي ينص على "توجد فروق ذات دلالة إحصائية عند مستوى دلالة (20.05ه) بين متوسطي درجات طلاب المجموعة التجريبية وطلاب المجموعة الضابطة في التطبيق البعدي لمقياس تحقيق الذات وأبعاده تعزى لصالح المجموعة

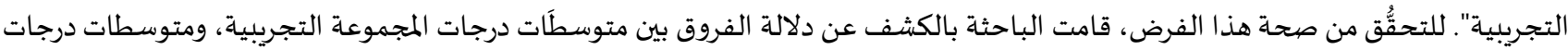
المجموعة الضابطة على مقياس تحقيق الذات بعد تطبيق البرنامج، وذلك باستخدام اختبار "ت" Test - T، لعينتين مستقلتين (صلاح مراد، 2000:

243) والجدول التالي يوضح النتائج: 


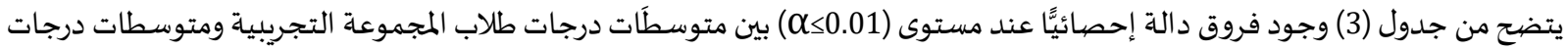

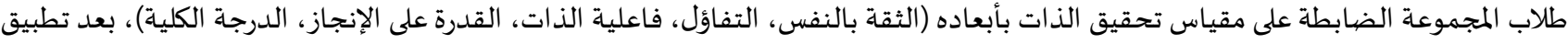

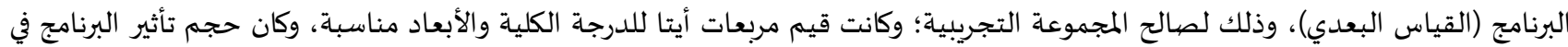

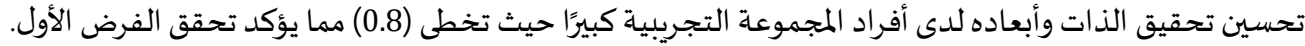

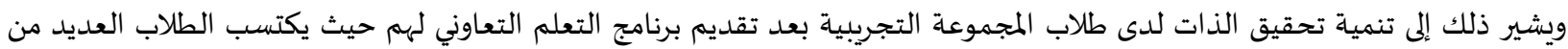

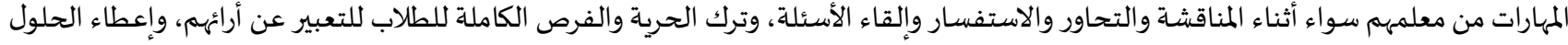

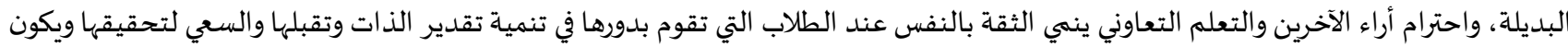

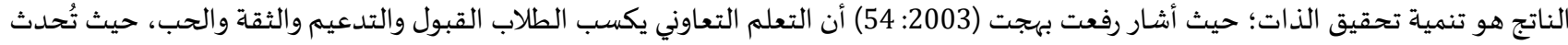

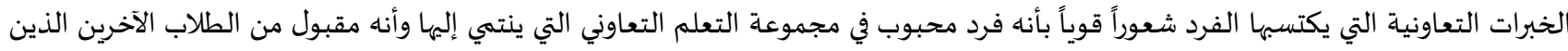

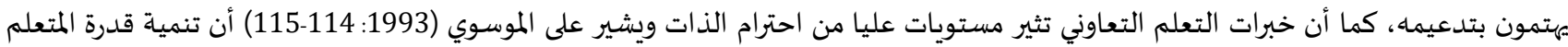

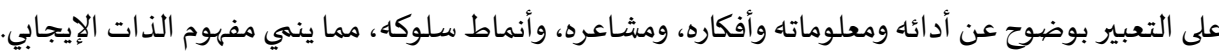

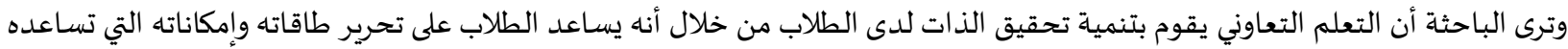

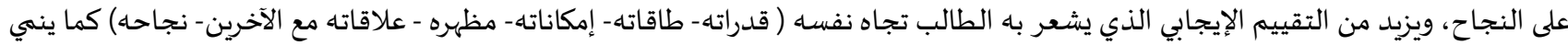

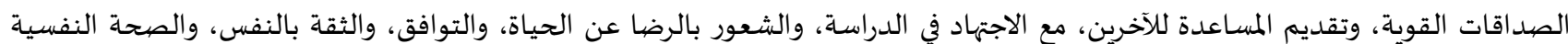

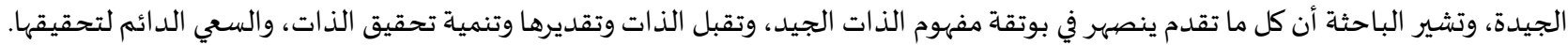

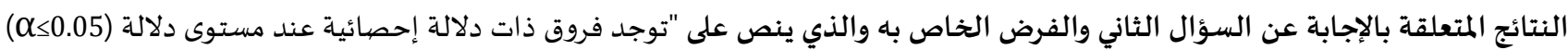

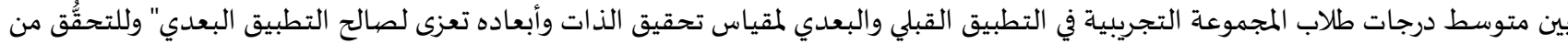

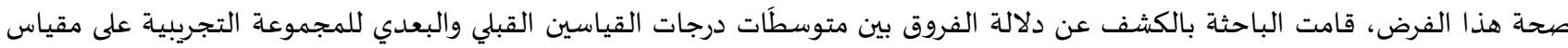

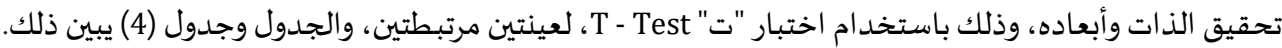

\begin{tabular}{|c|c|c|c|c|c|c|c|c|}
\hline حجم التأثير & قيمة & الدلالة & قيمة & الحربة & المعياري & الحسابي & نوع التطبيق & $\begin{array}{l}\text { المقياس } \\
\text { أبعاد }\end{array}$ \\
\hline 0,938 & 0,566 & دالة عند & 18,927 & 29 & $\begin{array}{l}4,344 \\
3,830\end{array}$ & $\begin{array}{l}17,866 \\
31,866\end{array}$ & البعدي & الثقة بالنفس \\
\hline 0,954 & 0,618 & دالة عند & 23,473 & 29 & $\begin{array}{l}3,122 \\
4,157\end{array}$ & $\begin{array}{r}15,2000 \\
31,766\end{array}$ & البعدي & التفاؤل \\
\hline 0,951 & 0,607 & دالة عند & 22,442 & 29 & $\begin{array}{l}3,170 \\
3,772\end{array}$ & $\begin{array}{c}14,533 \\
31,9000\end{array}$ & البعدي & فاعلية الذات \\
\hline 0,938 & 0,566 & دالة عند & 18,183 & 29 & $\begin{array}{l}3,342 \\
4,566\end{array}$ & $\begin{array}{c}17 \\
32,333\end{array}$ & البعدبي & الإنداز على \\
\hline 0,971 & 0.675 & دالة عند & 30,075 & 29 & $\begin{array}{c}8,015 \\
14,929\end{array}$ & $\begin{array}{l}64,6000 \\
127,866\end{array}$ & البعدي & الدرجة الكلية \\
\hline
\end{tabular}

بتضح من جدول (4) وجود فروق دالة إحصائياً بين متوسطات درجات القياسين القبلي والبعدي للمجموعة التجريبية على مقياس تحقيق الذات

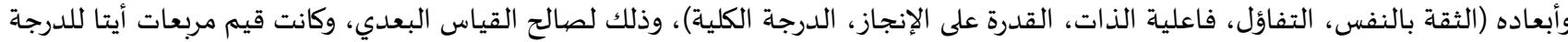

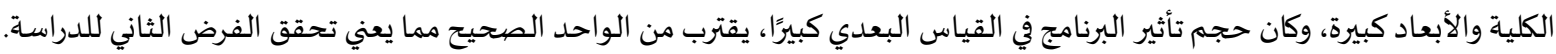

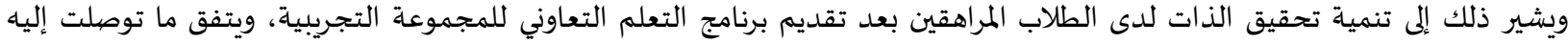
الباحثة من نتائج مع دراسة جميل الفاخوري (122:1992)؛ ودراسة سهير سليم (1998: 139) ويمكن تفسير هذه النتيجة على أن التعلم التعاوني لهاتيه

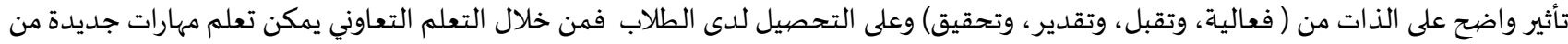
خلال ملاحظة الآخرين والتواصل معهم من أجل التعلم فيؤدي ذلك لرفع مستوى فعالية الذاتئ الذات للتعلم، وتقبلها، وتقديرها والسعي الدائم لتحقيقها

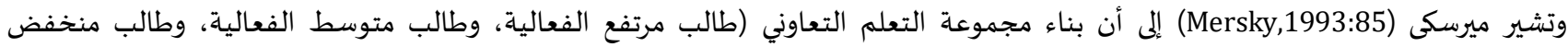

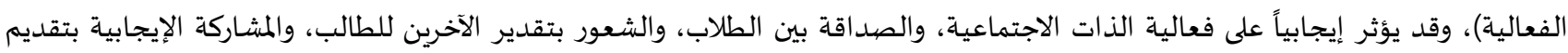

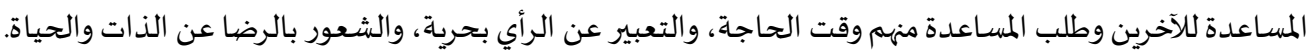


ترى الباحثة أن أنشطة التعلم التعاوني تساعد الطالب على فهمه لذاته ولقدراته وإمكاناته، فيسعى لتحقيق ذاته في ضوء قدراته وإمكاناته حيث

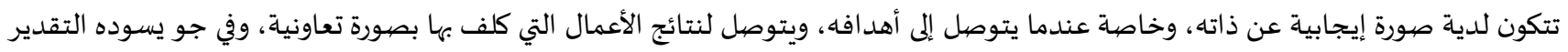

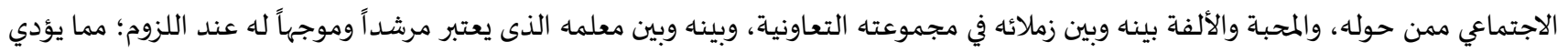

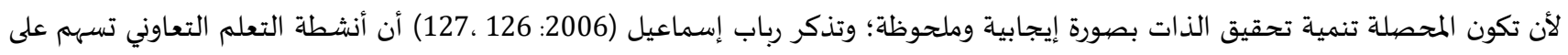

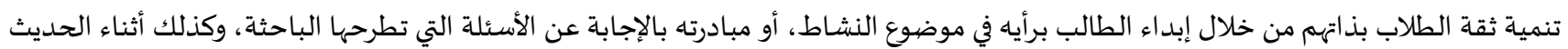

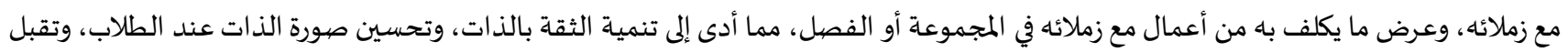

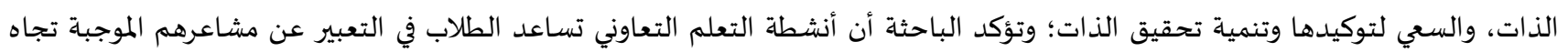

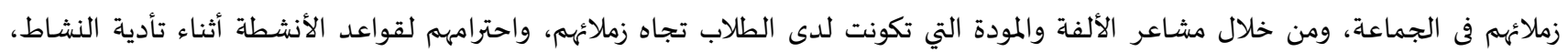

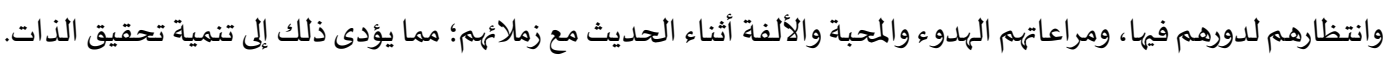

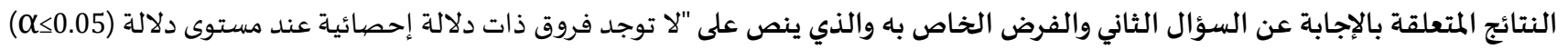

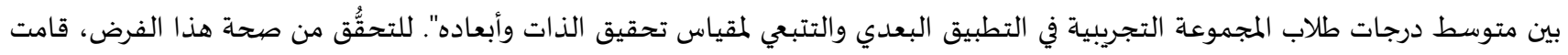

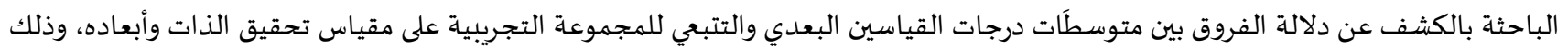

باستخدام اختبار "ت" لعينتين مرتبطتين، والجدول التالي يبين نتائج التحليل.

\begin{tabular}{|c|c|c|c|c|c|c|}
\hline sig الدلالة & قيمة (ت) & الحربة & الانحراف المعياري & المتوسط & نوع التطبيق & القياس \\
\hline \multirow{2}{*}{ غير دالة } & \multirow{2}{*}{0,294} & \multirow{2}{*}{29} & 3,830 & 31,866 & البعدي & \multirow{2}{*}{ الثقة بالنفس } \\
\hline & & & 3,266 & 32,133 & التتبعي & \\
\hline \multirow{2}{*}{ غير دالة } & \multirow{2}{*}{0,051} & \multirow{2}{*}{29} & 4,157 & 31,766 & البعدي & \multirow{2}{*}{ التفاؤل } \\
\hline & & & 2,911 & 31,733 & التبعي & \\
\hline \multirow{2}{*}{ غير دالة } & \multirow{2}{*}{0,491} & \multirow{2}{*}{29} & 3,772 & 31,9000 & البعدي & \multirow{2}{*}{ فاعلية الذات } \\
\hline & & & 3,190 & 31,6000 & التبعي & \\
\hline \multirow{2}{*}{ غير دالة } & \multirow{2}{*}{1,056} & \multirow{2}{*}{29} & 4,566 & 32,333 & البعدي & \multirow{2}{*}{ القدرة على الإنجاز } \\
\hline & & & 3,908 & 31,966 & التبعي & \\
\hline \multirow{2}{*}{ غير دالة } & \multirow{2}{*}{0,717} & \multirow{2}{*}{29} & 14,929 & 127,866 & البعدي & \multirow{2}{*}{ الدرجة الكلية } \\
\hline & & & 7,902 & 126,4000 & التتبعي & \\
\hline
\end{tabular}

يتضح من جدول (5) عدم وجود فروق دالة إحصائياً بين متوسطات درجات القياسين البعدي والتتبعي للمجموعة التجريبية على مقياس تحقيق

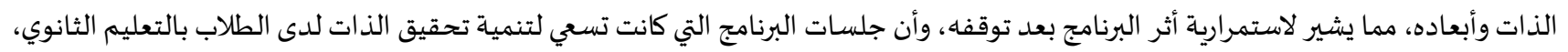

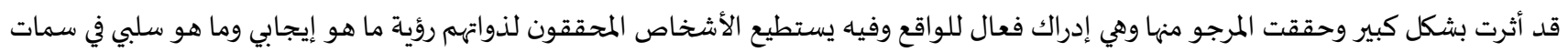

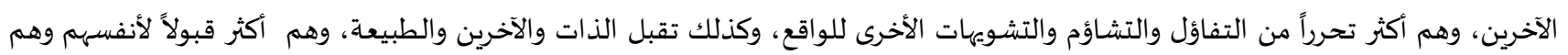
يعرفون نقاط قوتهم وضعفهم، وهم بنفس الأسلوب يتقبلون الآخرين دون حاجة إلى تغييرهم ولا يتوقعون الكمال في أنفسهم أو الآخرين، وأقل ميلاً

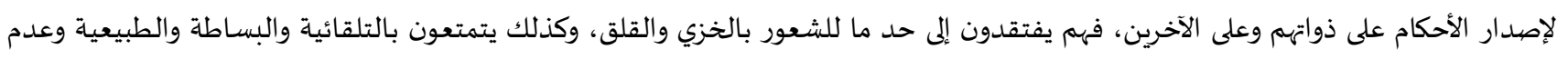

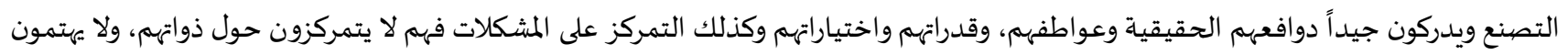

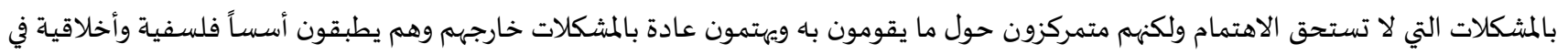

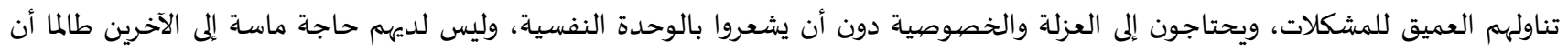

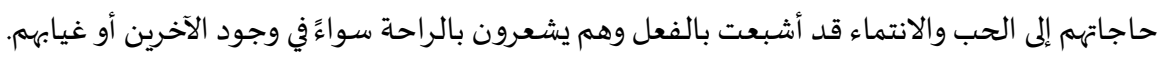
توصيات الدراسـة: توصي الدراسة بما يلي: 1. تضمين المناهج التعليمية لأنشطة وطرق تدريس تسههم في تنمية تحقيق الذات لدى الطلاب.

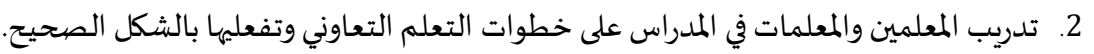
3. الاهتمام بالبيئة الصفية الجيدة التي تشجع الطالب على التفاعل المثثمر مع وزملائه والمعلم وطرح آرائه وافكاره في جو من الديمقراطية لتحقيق

1. الضبط الانفعالي وعلاقتاء بتحقيق الذات لدى طلاب المرحلة الثانوية. 
2. أثر التعلم التعاوني على دافعياة الانجاز والتحصيل لدى طلاب المرحلة الثانوية. 3. أثر المناخ الأسري على تحقيق الذات لدى طلاب المرحلة الثانوية.

المراجع:

أولاً: المراجع العربية:

1. إبراهيم أحمد بهلول (2012). فعالية استخدام احسلهى استراتيجيات التعلم التعاوني في كل من التحصيل النحوي واستبقاء المعلومات والاتجاه نحو المادة النحوية لدى تلامين الصفف الثاني الإعد/دي. مجلة كلية التربية: بالمنصورة. 50: 2-62

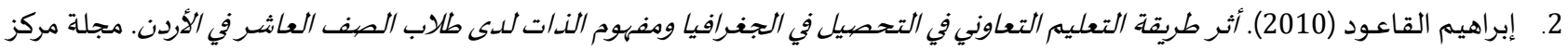
البحوث التربوية: جامعة قطر. $4(7)$ (7): 131 - 172.

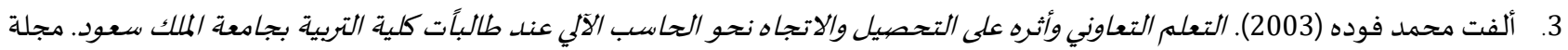
رسالة الخليج. $23(86)$ (201): 85 - 108.

4. تلي عبد الرحمن (2013). تحقيق الذات نهاية سلم للحاجات أم بداية للتعاون ؟." مجلة الحكمة: (30): 8 - 15.

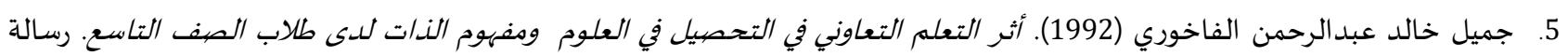
ماجستير(غير منشورة). جامعة اليرموك. إربد. الأردن .

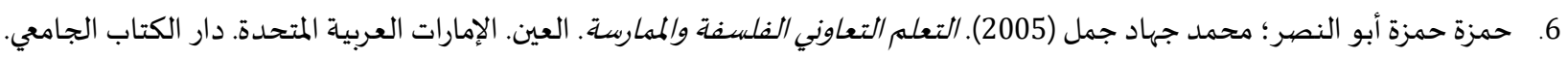
7. خضر مخيمر؛ أبو زبد محمد (2014). ملدى فاعلية استخدل/م استراتيجية التعلم التعاوني فى تنمية الدافعية والتحصيل الدراسي والقابلية للعمل

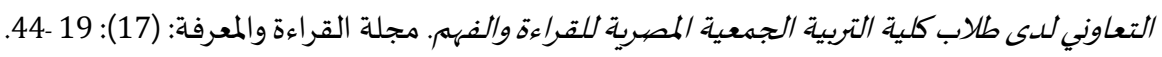
8. رباب صلاح الدين إسماعيل (2006). فعالية التعليم التعاوني في تنمية توكيد الذات لدى أطفال الروضية. رسالة ماجستير (غير منشورة). كلية التربية. جامعة المنصورة. 9 9. رفعت محمود بهجات (2003). التعلم الاستراتيجي مدخل مقترح لحفز التفكير العلمي. القاهرة: عالم الكتب . 10. زبيدة أمزيان (2007). علاقة تقدير الذات للمراهق بمشككلاته وحاجاته الاششادية دراسة مقارنة في ضوء متغير الجنس. رسالة ماجستير في علم

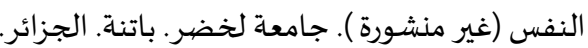

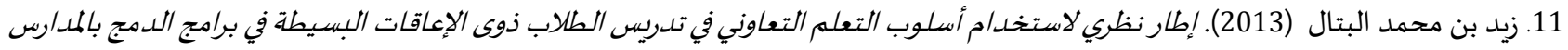

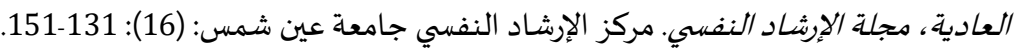

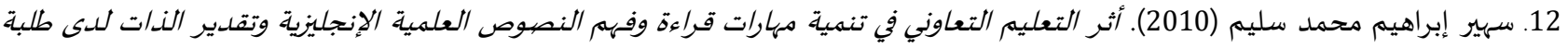

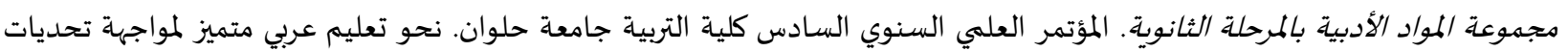
متجددة. 3: 139-117. 13. صالح فؤاد الشعراوي (2011). العلاقة بين تحقيق الذدات والقدرة الابتكارية لدى عينة من طلبة الجامعة. رسالة ماجستير (غير منشورة). كلية التربية جامعة الزقازيق. 14. صلاح الدين حسين الشريف (2000). ملدى فعالية الستراتيجيات التعلهم التعاوني في علاج صعوبات تعلم الرياضيات وتقلدير الذات. مجلة كلية التربية جامعة أسيوط: 16(1): 227- 269.

15. صلاح أحمد مراد (2000). الأساليب الإحصيائية في العلوم النفسية والتوبوية والاجتماعية. القاهرة: مكتبة الأنجلو المصرية. 16. طلعت منصور؛ وفيولا الببلاوي (2005). اختبار التوجه الشخصي وقياس تحقيق الذات. القاهرة: مكتبة الأنجلو المصرية. 17. عادل إبراهيم شوشان (2013). اثر برنامج قائم على التعلم التعاوني في تنمية مهارات التفكير وفاعلية الذات الأكاديمية في مادة اللغنة الانجليزية

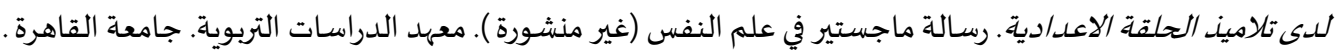
18. عادل صلاح عبد الجبار (2002). العلاقة بين التوكيدية وتحقيق الذات لدى طلاب الجامعة. دراسات طفولة (نفسية اجتماعية إعلامية طبية). $.68-43:(15)$ 19. عادل يحيى محمد (2014). ملدى فعالية برنامج للتعلم التعاوني والفردي بالحاسوب على التحصيل الدرامسي لتلامين المرحلة الابتدائية. مجلة كلية التربية جامعة المنصيورة: (56): 131-165. بحمئ 20. عبادة أحمد عبادة الخولى (1997). أثر استخدام استراتيجية التعلم التعاوني في تلدريس مقرر الأجهة والمعددات الكههبية لتلاميذ الصهف الثاني

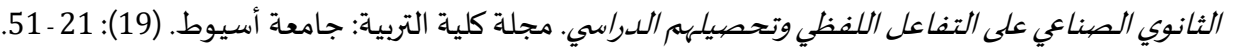


21. عبد الرزاق همام سويلم؛ خليل رضوان سليمان (2001). فعالية استراتيجية مقترحة في التعلم التعاوني على التحصيل وههارات الاتصال

والاتجاهات نحو العلوم لدى تلاميذ الصهم. مجلة التربية وعلم النفس: جامعة المنيا. ج(14) (ع3): 179-203.

22. عبد اللطيف بن صالح النعيم (2010). المتغيرات المؤثرة على الشعور بتحقيق الندات للدى عضيو هيئة التدريس بكلية الشيرية في محافظة

الأحساء بالمملكة العببية السعودية. المجلة العلمية للبحوث والدراسات التجارية: (3): 265 - 332.

23. عبد المطلب أمين القريطى (2001). سيكولوجية ذوى الاحتياجات الخاصة وترتيبهم. القاهرة : دار الفكر العربي.

24. عزيز حناء محمد عبد الظاهر؛ وناظم هاشم (2002). الشخصية بين السواء والممض. (ط2). القاهرة: مكتبة الأنجلو المصرية.

25. غازي ضيف الله غازي العتيبي (2010). ضغنوط العمل وعلاقتها بتحقيق الذات للدى الممديرين الكويتيين. رسالة ماجستير (غير منشورة). كلية

الآداب. جامعة الزقازيق.

26. فوزية عبد الباقي الحاج علي (2009). دراسة العلاقة بين تحقيق الذات والمناخ الأسرى لدى الشباب الجامعي في بعض دول الخليج، رسالة

$$
\text { ماجستير (غير منشور). كلية التربية. جامعة الزقازيق . }
$$

27. لويس كامل مليكة (2001). التحليل النفسي والمفهوم الإنساني في العلاج النفسي. (ط2) القاهرة :مكتبة النهضية العبربية.

28. محمد إبراهيم عيد (2012). الهوية والقلق والإبداع. القاهرة: دار القاهرة.

29. مضتي ساير حميد المصلوخي (2012). العلاقة بين الضغوط النفسية وتحقيق الندات لدى طلاب الممحلة الثانوية بمدينة الرياض بالمملكاة العربية

السعودية. مجلة التربية: جامعة الأزهر. $4(51)$ (51): 205 - 248.

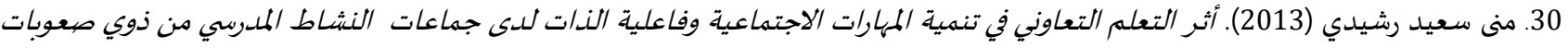

التعلم بلدولة الكويت. رسالة ماجستير في علم النفس (غير منشورة ). معهد الدراسات التربوية. جامعة القاهرة .

31. نادية محمود محمد بنداري (2012). دراسة للدافع المعرفي وعلاقته بالحاجة لتحقيق الذات عند طلاب الممحلة الثانوية العامة. رسالة ماجستير

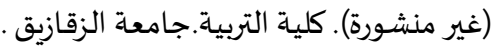

32. نبيل حافظ (2013). الابتكارية وتحقيق الذات للدى طلاب الدراسات العليا التويوية. مجلة كلية التربية: جامعة عين شمس. 1(18): 57-86.

33. هدى عبد الحميد عبد الفتاح (2014). أثر استخدام التعلم التعاوني في تدريس العلوم في تنمية التفكير العلمي للدى تلاميذ المرحلة الإعلدادية.

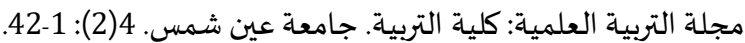

ثانياً: المراجع الأجنبية:

1. Brandt, F. J. \& Ellsworth (2011). Effect of Cooperative learning on Academic Achievement and self-esteem of Urban. Adolescents with learning Disabilities: Multidisciplinary Journal, 7(9):13 -26.

2. Caissi, R. Wilson, E (2009). Communication breakdown management during Cooperative learning activities by mainstreamed students with hearing Losses Review. Education and Deafness, 97(2): 105- 121.

3. Cer, E \& sahin, E (2017). The effects of Quality Books for children and the metacognitive Strategy on students Self - Esteem levels. Journal of Education and learning, 6(1): 72-80, https://doi.org/10.5539/jel.v6n1p72.

4. Davidson, N. (2006). Small Group Cooperative learning in mathematics-teaching and Learning mathematics book (NCTM).

5. Johnnie, E. (2002). Facilitating Self - Actualization in high School Youth Faculty Strategies. U- S - A, ProQuest in formation. And learning Company.

6. Jocobs, D \& et.al (2011). Effects of Cooperative Method on Mathematics Achievement and Affective outcomes of Students in private elementary School. Journal of Research and Development in Education, 25 (4): 95 - 202.

7. Johnson, D, Johnson, R\& Smith, k. (2000). Cooperative learning Returns to College: in Deborach Dezure (Ed) learning from change, London, Stylus Publishing.

8. Lee, M \& luck, R. (2015). What and how of Cooperative learning. The Social Studies, 28 (3): 122-135.

9. Mersky, K. H. (1993). Social Self- efficacy and adaptive Social Interaction: Analysis of the relationship between beliefs group processes and knowledge gain. Dissertation Abstracts International, 54(1): 48.

10. Nichols. J. D. \& Miller, R. B. (2007). The Effects of Cooperative learning on Student Achievement and Motivation in High School Geometry Class, paper presented at the Annual Meeting of the American Educational Research Associations, SanFrancisco, CA, April.

11. Punch, K. F. \& Beverly, B. (1997). Cooperative and Competitive learning environments and their effects on behaviour, Self- efficacy and Achievement. Alberta Journal of Educational Research, (43): 158 -170. 
المجلة الدولية للدراسـات التربوية والنفسية

International Journal of Educational \& Psychological Studies (EPS)

Journal Homepage: https://www.refaad.com/views/EPSR/Home.aspx

www.refaad.com

ISSN: 2520-4149 (Online) 2520-4130 (Print)

\title{
Effectiveness of a program based on cooperative learning and its impact on the development of self-realization among secondary school students
}

\author{
Naglaa Fathy Abdel Rahman Al-Shimi \\ Assistant Professor of Psychology and Psychological Health, Faculty of Science and Arts, Sharurah, Najran \\ University, KSA \\ aldoktor_2014@yahoo.com
}

Received : 7/10/2020 Revised : 11/11/2020 Accepted : 14/1/2021 DOI : https://doi.org/10.31559/EPS2021.9.3.10

Abstract: The study aimed to verify the effectiveness of a training program based on cooperative learning in developing self-realization among third-grade secondary students, and to verify the continuing impact of the program on the sample.

The sample of the study consisted of (60) students divided into two equal groups, a control group and the other experimental, and the study tools were (Self-Achievement Scale) using the experimental approach, The results showed that there were statistically significant differences between the average scores of the experimental and control groups on the Self-Achievement Scale and its dimensions in the post-measurement, in favor of the experimental group, as well as the existence of statistically significant differences between the average scores of the experimental group in the two measures (pre and post) in favor of the postmeasurement on the Self-Achievement Scale and its dimensions. Likewise, there are no statistically significant differences between the average scores of the experimental group members on the SelfAchievement Scale in the post and tracer measurements, i.e. the continuity of the program's effectiveness that the experimental group was exposed to. One of the most important recommendations of the study is the inclusion of educational curricula for activities and teaching methods that contribute to the development of students 'self-realization.

Keywords: Collaborative Learning; Self-realization; training program.

\section{References:}

1. 'adl Ebrahym Shwshan (2013). Athr Brnamj Qa'm 'la Alt'lm Alt'eawny Fy Tnmyh Mharat Altfkyr Wfa'lyt Aldat Alakadymyh Fy Madh Allghh Alanjlyzyh Lda Tlamyd Alhlqh Ala'dadyh. Rsalt Majstyr Fy 'Im Alnfs (Ghyr Mnshwrh). M'ehd Aldrasat Altrbwyh. Jam't Alqahrh.

2. 'adl Slah 'bd Aljbar (2002). Al'laqh Byn Altwkydyh Wthqyq Aldat Lda Tlab Aljam'h. Drasat Tfwlh (Nfsyh Ajtma'yh E'lamyh Tbyh). (15): $43-68$.

3. 'adl Yhya Mhmd (2014). Mda F'alyt Brnamj Llt'lm Alt'eawny Walfrdy Balhaswb 'la Althsyl Aldrasy Ltlamyd Almrhlh Alabtda'yh. Mjlt Klyt Altrbyh Jam't Almnswrh: (56): 131-165.

4. 'badh Ahmd 'badh Alkhwla (1997). Athr Astkhdam Astratyjyh Alt'lm Alt'awny Fy Tdrys Mqrr Alajhzh Walm'dat Alkhrbyh Ltlamyd Alsf Althany Althanwy Alsna'y 'la Altfa'l Allfzy Wthsylhm Aldrasy. Mjlh Klyh Altrbyh: Jam't Asywt. (19): 21 - 51.

5. 'bd Alrzaq Hmam Swylm: Khlyl Rdwan Slyman (2001). F'alyt Astratyjyh Mqtrhh Fy Alt'lm Alt'awny 'la Althsyl Wmharat Alatsal Walatjahat Nhw Al'lwm Lda Tlamyd Alsm. Mjlt Altrbyh W'Im Alnfs: Jam't Almnya. J(14) ('3): 179-203.

6. 'bd Alltyf Bn Salh Aln'eym (2010). Almtghyrat Alm'thrh 'la Alsh'wr Bthqyq Aldat Lda 'dw Hy't Altdrys Bklyt Alshry'eh Fy Mhafzh Alahsa' Balmmlkh Al'rbyh Als'wdyh. Almjlh Al'lmyh Llbhwth Waldrasat Altjaryh: (3): 265 - 332.

7. 'bd Almtlb Amyn Alqryta (2001). Sykwlwjyh Dwa Alahtyajat Alkhash Wtrtybhm. Alqahrh: Dar Alfkr Al'rby.

8. 'zyz Hna: Mhmd 'bd Alzahr: Wnazm Hashm (2002). Alshkhsyh Byn Alswa' Walmrd. (T2). Alqahrh: Mktbt Alanjlw Almsryh. 
9. Alft Mhmd Fwdh (2003). Alt'lm Alt'awny Wathrh 'la Althsyl Walatjah Nhw Alhasb Alaly 'nd Talbaant Klyt Altrbyh Bjam't Almlk S'wd. Mjlt Rsalh Alkhlyj. 23(86): 85 - 108.

10. Ebrahym Ahmd Bhlwl (2012). F'alyt Astkhdam Ahda Astratyjyat Alt'lm Alt'awny Fa Kl Mn Althsyl Alnhwy Wastbqa' Alm'lwmat Walatjah Nhw Almadh Alnhwyh Lda Tlamyd Alsf Althany Ale'dady. Mjlt Klyt Altrbyh: Balmnswrh. 50: 2-62

11. Ebrahym Alqa'wd (2010). Athr Tryqh Alt'lym Alt'awny Fy Althsyl Fy Aljghrafya Wmfhwm Aldat Lda Tlab Alsf Al'ashr Fy Alardn. Mjlt Mrkz Albhwth Altrbwyh: Jam't Qtr. 4(7): 131 - 172.

12. Fwzyh 'bd Albaqy Alhaj 'ly (2009). Drast Al'laqh Byn Thqyq Aldat Walmnakh Alasra Lda Alshbab Aljam'y Fy B'd Dwl Alkhlyj, Rsalt Majstyr (Ghyr Mnshwr). Klyt Altrbyh. Jam't Alzqazyq .

13. Ghazy Dyf Allh Ghazy Al'tyby (2010). Dghwt Al'ml W'laqtha Bthqyq Aldat Lda Almdyryn Alkwytyyn. Rsalt Majstyr (Ghyr Mnshwrh). Klyt Aladab. Jam't Alzqazyq.

14. Hda 'bd Alhmyd 'bd Alftah (2014). Athr Astkhdam Alt'lm Alt'awny Fa Tdrys Al'lwm Fa Tnmyt Altfkyr Al'lmy Lda Tlamyd Almrhlh Ale'dadyh. Mjlt Altrbyh Al'lmyh: Klyt Altrbyh. Jam't 'yn Shms. 4(2): 1-42.

15. Hmzh Hmzh Abw Alnsr: Mhmd Jhad Jml (2005). Alt'lm Alt'awny Alflsfh Walmmarsh. Al'yn. Alemarat Al'rbyh Almthdh. Dar Alktab Aljam'y.

16. Jmyl Khald 'bdalrhmn Alfakhwry (1992). Athr Alt'lm Alt'awny Fy Althsyl Fy Al'lwm Wmfhwm Aldat Lda Tlab Alsf Altas'e. Rsalt Majstyr(Ghyr Mnshwrh). Jam't Alyrmwk. Erbd. Alardn .

17. Khdr Mkhymr: Abw Zyd Mhmd (2014). Mda Fa'lyt Astkhdam Astratyjyh Alt'lm Alt'awny Fa Tnmyt Aldaf'yh Walthsyl Aldrasy Walqablyh Ll'ml Alt'awny Lda Tlab Klyt Altrbyh Aljm'yh Almsryh Llqra'h Walfhm. Mjlt Alqra'h Walm'rfh: (17): 19 -44 .

18. Lwys Kaml Mlykh (2001). Althlyl Alnfsy Walmfhwm Alensany Fy Al'laj Alnfsy. (T2) Alqahrh: Mktbt Alnhdh Al'rbyh.

19. Mdhy Sayr Hmyd Almslwkhy (2012). Al'laqh Byn Aldghwt Alnfsyh Wthqyq Aldat Lda Tlab Almrhlh Althanwyh Bmdynh Alryad Balmmlkh Al'rbyh Als'wdyh. Mjlt Altrbyh: Jam't Alazhr. 4(51): 205 - 248.

20. Mhmd Ebrahym 'yd (2012). Alhwyh Walqlq Walebda'. Alqahrh: Dar Alqahrh.

21. Mna S'yd Rshydy (2013). Athr Alt'lm Alt'awny Fy Tnmyt Almharat Alajtma'yh Wfa'lyt Aldat Lda Jma'at Alnshat Almdrsy Mn Dwy S'wbat Alt'lm Bdwlh Alkwyt. Rsalt Majstyr Fy 'Im Alnfs (Ghyr Mnshwrh). M'hd Aldrasat Altrbwyh. Jam't Alqahrh.

22. Nadyh Mhmwd Mhmd Bndary (2012). Drash Lldaf' Alm'rfy W'laqth Balhajh Lthqyq Aldat 'nd Tlab Almrhlh Althanwyh Al'amh. Rsalt Majstyr (Ghyr Mnshwrh). Klyt Altrbyh. Jam't Alzqazyq .

23. Nbyl Hafz (2013). Alabtkaryh Wthqyq Aldat Lda Tlab Aldrasat Al'lya Altrbwyh. Mjlt Klyt Altrbyh: Jam't 'yn Shms. 1(18): 57-86.

24. Rbab Slah Aldyn Esma'yl (2006). F'alyt Alt'lym Alt'awny Fy Tnmyt Twkyd Aldat Lda Atfal Alrwdh. Rsalt Majstyr (Ghyr Mnshwrh). Klyt Altrbyh. Jam't Almnswrh.

25. Rf't Mhmwd Bhjat (2003). Alt'lm Alastratyjy Mdkhl Mqtrh Lhfz Altfkyr Al'lmy. Alqahrh: 'alm Alktb.

26. Slah Aldyn Hsyn Alshryf (2000). Mda F'alyt Astratyjyat Alt'lm Alt'awny Fy 'laj S'wbat T'lm Alryadyat Wtqdyr Aldat. Mjlt Klyt Altrbyh Jam't Asywt: 16(1): 227- 269.

27. Slah Ahmd Mrad (2000). Alasalyb Alehsa'yh Fa Al'lwm Alnfsyh Waltrbwyh Walajtma'yh. Alqahrh: Mktbt Alanjlw Almsryh.

28. Salh F'ad Alsh'rawy (2011). Al'laqh Byn Thqyq Aldat Walqdrh Alabtkaryh Lda 'ynh Mn Tlbt Aljam'h. Rsalt Majstyr (Ghyr Mnshwrh). Klyt Altrbyh Jam't Alzqazyq.

29. Shyr Ebrahym Mhmd Slym (2010). Athr Alt'lym Alt'awny Fy Tnmyt Mharat Qra'h Wfhm Alnsws Al'lmyh Alenjlyzyh Wtqdyr Aldat Lda Tlbt Mjmw't Almwad Aladbyh Balmrhlh Althanwyh. Alm'tmr Al'lmy Alsnwy Alsads Klyt Altrbyh Jam't Hlwan. Nhw T'lym 'rby Mtmyz Lmwajhh Thdyat Mtjddh. 3: 117-139.

30. Tl't Mnswr؛ Wfywla Albblawy (2005). Akhtbar Altwjh Alshkhsy Wqyas Thqyq Aldat. Alqahrh: Mktbt Alanjlw Almsryh.

31. Tly 'bdalrhmn (2013). Thqyq Aldat Nhayh Slm Llhajat Am Bdayt Llt'awn?." Mjlt Alhkmh: (30): 8 - 15.

32. Zbydh Amzyan (2007). 'laqt Tqdyr Aldat Llmrahq Bmshklath Whajath Alarshadyh Drast Mqarnh Fy Dw' Mtghyr Aljns. Rsalt Majstyr Fy 'Im Alnfs (Ghyr Mnshwrh). Jam't Lkhdr. Batnh. Aljza'r.

33. Zyd Bn Mhmd Albtal (2013). Etar Nzry Lastkhdam Aslwb Alt'lm Alt'awny Fy Tdrys Altlab Dwa Ale'aqat Albsyth Fy Bramj Aldmj Balmdars Al'adyh, Mjlt Alershad Alnfsy. Mrkz Alershad Alnfsy Jam't 'yn Shms: (16): 131-151. 